\title{
Noncovalent Interactions in Organometallic Chemistry: from Cohesion to Reactivity, a new Chapter.
}

\author{
Yann Cornaton and Jean-Pierre Djukic*.
}

Laboratoire de Chimie et Systémique Organométallique, Institut de Chimie de Strasbourg UMR7177, CNRS - Université de Strasbourg, 4 rue Blaise Pascal, F-67070 Strasbourg, France.

* corresponding author, E-mail: djukic@unistra.fr 
Conspectus. Noncovalent interactions (NCIs) have long interested a vast community of chemists who investigated their "canonical categories" derived from descriptive crystallography, e.g H-bond, $\pi-\pi$ interaction, halogen-chalcogen-tetrel bonds, cation and $\mathrm{C}-\mathrm{H}-\pi$ interactions, metallophilic interactions in the broad sense, etc... Recent developments in theoretical chemistry enable the treatment of noncovalent interactions under new auspices: dispersion forceinclusive density functionals have emerged, which are reliable for modeling small to large molecular systems. It is possible to perform the full analysis of the contributions of London, Debye and Keesom forces, i.e. the main components of van der Waals (vdW) forces, by the DFT-D and ab initio methods at a reasonable computational cost. Our research has been focusing for now 15 years on the role of NCIs in the cohesion of organometallic complexes. NCIs are not only effective in Werner's secondary coordination sphere but also in metal's primary one. The stabilization of electron unsaturated transition metal complexes by hemichelation, metal-metal donor acceptor complexes, the self-aggregation of cationic $\mathrm{Rh}(\mathrm{I})$ chromophores have indeed outlined the significance of London Dispersion force (LDF) as an attractive force operating throughout the whole molecule or molecular assembly. The recent outburst of interest for $\mathrm{C}-\mathrm{H}$ bond functionalization led us to address the broader question of reaction and catalyst engineering: although one can now satisfactorily analyze bonding and molecular cohesion in transition metal-based organometallic systems, can modern theoretical methods guide reactivity exploration and the engineering of novel catalytic systems ? We addressed this question by investigating the Ambiphilic Metal-Ligand Activation/Concerted Metalation Deprotonation (AMLA/CMD) mechanism involved in the transition metal-catalysed directed $\mathrm{C}-\mathrm{H}$ bond functionalization. This endeavor was initiated having in scope the construction of a rationale for the transposition of $4-5 \mathrm{~d}$ metal chemistry to earth-abundant $3 d$ metals. In this base-assisted mechanism of $\mathrm{C}-\mathrm{H}$ bond metalation, agostic interactions are necessary but not sufficient, for $\mathrm{C}-\mathrm{H}$ bond breaking actually relies on the attractive NCI-coding of a proton-transfer step and the minimization of metal-H repulsion. This account introduces the recent shift of our research towards the construction of a NCI-inclusive paradigm of chemical reactivity engineering based on experimental efforts propped up by state-of-the-art theoretical tools. 


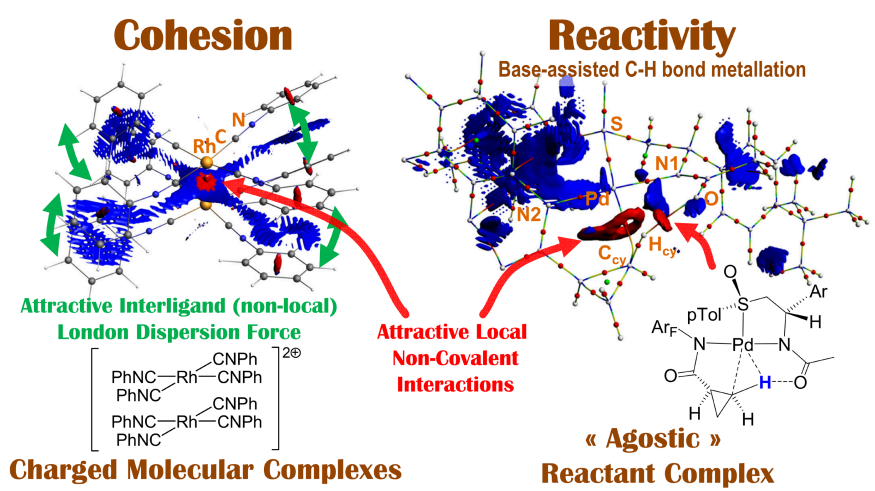




\section{Key References}

-Grimme, S.; Djukic, J.-P., Cation-Cation "Attraction": When London Dispersion Attraction Wins over Coulomb Repulsion Inorg. Chem. 2011, 50, 2619-2628. Charge screening and noncovalent interactions are responsible for the spontaneous self-aggregation of tetrakis(arylisonitrile)rhodium(I) cations in polar solvents.

-Werle, C.; Bailly, C.; Karmazin-Brelot, L.; Le Goff, X.-F.; Ricard, L.; Djukic, J.-P., Hemichelation, a way to stabilize electron-unsaturated complexes: the case of T-shaped Pd and Pt metallacycles J. Am. Chem. Soc. 2013, 135, 17839-17852. Electron deficient T-shaped Pd(II) complexes can be prepared under a persistent form thanks to hemichelation, a hybrid covalentnoncovalent heterochelation, which provides a thermodynamic stabilization superior to any other covalent alternatives.

-Cornaton, Y.; Djukic, J.-P., A noncovalent interaction insight onto the concerted metallation deprotonation mechanism Phys. Chem. Chem. Phys. 2019, 21, 20486-20498. The cyclometallation of N,N-dimethylbenzylamine by of Pd(II) and Ni(II) centres is subjected to Coulombic repulsion in the rate determining step of formation of a crucial agostic intermediate that can be minimized by adjusting the NCIs acting in the "reactive site".

-Wu, F.; Deraedt, C.; Cornaton, Y.; Contreras-Garcia, J.; Boucher, M.; Karmazin, L.; Bailly, C.; Djukic, J.-P., Making Base-Assisted $\mathrm{C}-\mathrm{H}$ Bond Activation by $\mathrm{Cp} * \mathrm{Co}(\mathrm{III})$ Effective: A Noncovalent Interaction-Inclusive Theoretical Insight and Experimental Validation Organometallics 2020, 39, 2609-2629. A thorough theoretical investigation of the Concerted Metallation Deprotonation mechanism of cyclocobaltation shows that high efficiency can be achieved by adjusting noncovalent interactions at the "reactive site" through a judicious choice of base, which was validated by experiment. 


\section{INTRODUCTION}

The recent revived interest for non-covalent interactions (NCIs) in chemical bonding ${ }^{1}$ and reactivity $^{2}$ in organometallic chemistry has been made possible by the concomitant development of DFT methods that include the long neglected London dispersion force (LDF). ${ }^{3}$ Although Eyring $^{4}$ united in 1932 the then existing quantum theories of chemical bonding and the theory of chemical reactivity into a consistent model of calculation of potential interaction energies that includes the LDF introduced 2 years earlier, ${ }^{5}$ very few reports on the relevance of LDF and NCIs (e.g. the tautological van der Waals forces) to reactivity showed up before the 1940s. The relevance of NCIs to the question of molecular cohesion and reactivity was first addressed by Bunnett $^{6}$ and Spinner ${ }^{7}$ two decades later to rationalize the kinetics of nucleophilic substitutions. ${ }^{8}$ Although the relevance of NCIs in defining reactivity and chemoselectivity has been debated for a century, ${ }^{9}$ their importance in reaction dynamics ${ }^{10}$ was only recently stressed as playing a crucial role in defining reaction activation energy barriers within the so-called "reactant complexes".

If the majority of recent studies consist of "a posteriori" investigations of the role of NCIs in metal-ligand or metal-metal bonding in organometallic compounds, ${ }^{11}$ the question of the role of NCIs in reactivity remains largely unaccounted. Here, we focus on the question of cohesion and the role of NCIs in isolable transition metal complexes, which furnishes the background for our current study of the factors determining the reactivity of organometallic compounds. 
a)

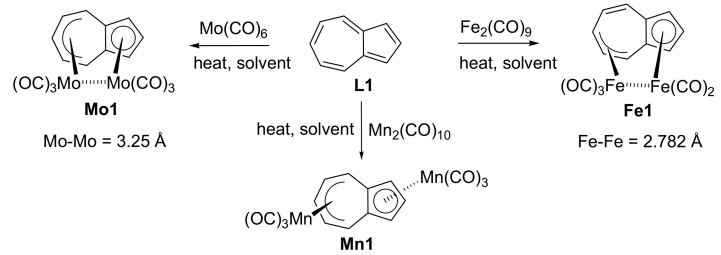

b)

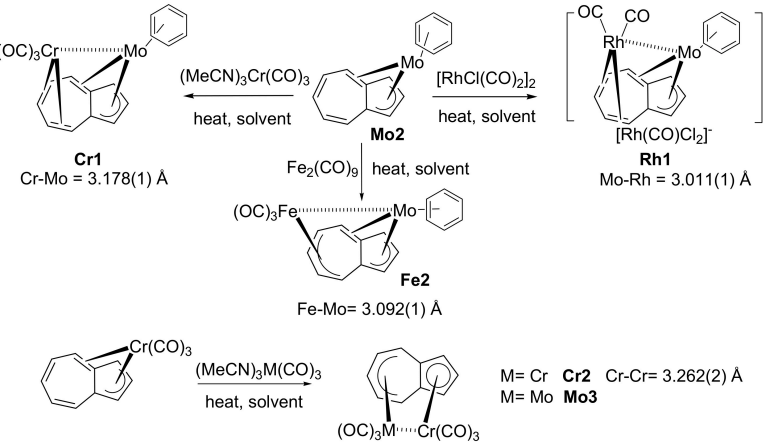

d)
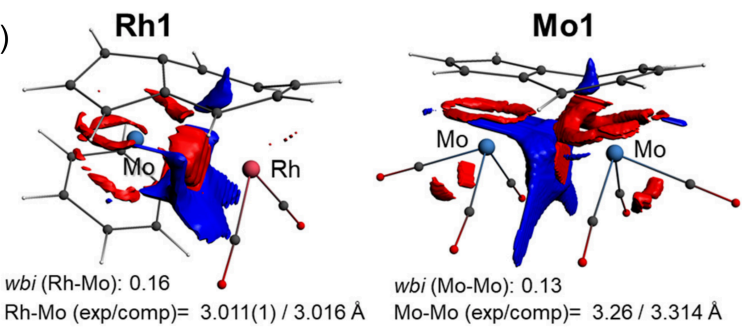

$\mathrm{Cr} 1$

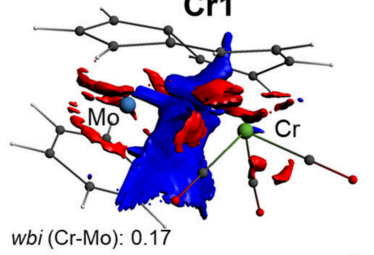

Cr-Mo $($ exp/comp $)=3.178(1) / 3.180 \AA$
Mo-Mo $($ exp/comp $)=3.26 / 3.314 \AA$

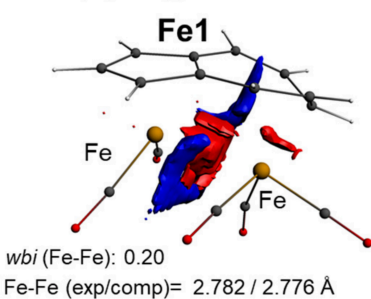

Figure 1. Revisiting historical cases reveals the importance of NCIs in organometallic cohesion. (a) The first occurrences (Mo1, Fe1 and Mn1 from L1) of the thermally favored suprafacial formation of homo and hetero-bimetallic azulene $\pi$-complexes. (b) and (c) Syntheses of Cr1, Fe2, Rh1 and Mo3 from Mo2. (d) ADF-NCI plot ${ }^{\partial, \dagger}$ analyses of chosen examples.

\section{Cohesion.}

Cohesion is the resultant of attractive and repulsive forces within a molecule or a molecular assembly. The question of the origin of cohesion influenced our research on isolable cases of electron-unsaturated transition metal complexes, which led to the emergence of hemichelation. ${ }^{1 \mathrm{~b}}$ Our interest extended to intermolecular complexes like those shown below.

\section{Syn-facial vs. anti-facial coordination and cohesion in organoheterobimetallic compounds.}

The central role of NCIs in structural cohesion can be readily figured nowadays by revisiting the founding organometallic chemistry of the 1950-60s that was long based on the descriptive crystallographic analysis of bonds. In the late 1950s, Wilkinson et al. reported the suprafacial synthesis of bimetallic complexes of azulene by the thermolytic treatment of the latter ligand with molybdenum and iron carbonyls. ${ }^{12}$ Later, Churchill et al. ${ }^{13}$ investigated further the coordination chemistry of azulenes and noted that the stereochemical course of the reaction could produce either syn-facial or anti-facial bimetallic complexes (Figure 1) leaving the preference for either isomers unaddressed. Behrens et al. ${ }^{14}$ showed that syn-facial 
heterobimetallic complexes could be synthesized by treating azulene Mo and $\mathrm{Cr}$ complexes with labile sources of $\mathrm{Cr}(\mathrm{CO})_{3}, \operatorname{Rh}(\mathrm{CO})_{2}{ }^{+}$and $\mathrm{Fe}(\mathrm{CO})_{3}$ fragments (Figure 1). However the authors expressed doubts about the existence of a covalent metal-metal bond due to the overly long intermetal distances measured by structural XRDA $\left(d>\Sigma r_{\mathrm{vdW}} \sim 2.8 \AA\right)$ and to the significant fluxionality of the complexes in solution. ${ }^{14 b, 14 \mathrm{c}}$ The analysis of these historical cases with the intuitive NCI $\operatorname{plot}^{15}$ tool ${ }^{\dagger}$ (Figure 1d) reveals the ubiquitous nature of local intermetallic attractive NCIs, suggesting above all that they could favor the intramolecular positioning of two metal centres close to each other. It must be stressed however that, by construction, NCI plot ${ }^{\dagger}$ only materializes NCI regions developing between weakly bonded fragments at close contact. Comprehensive descriptions of LDF and electron correlation energy contributions to cohesion from remote molecular fragments should better be sought at the WFT level (vide infra). ${ }^{1 \mathrm{a}, 16}$

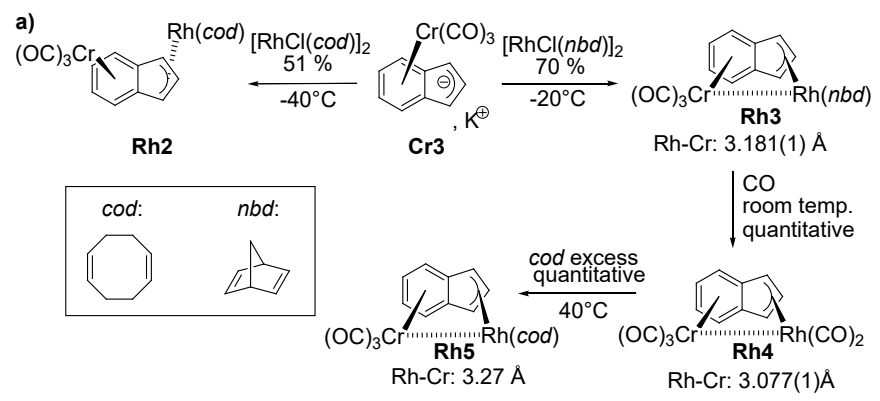

b)
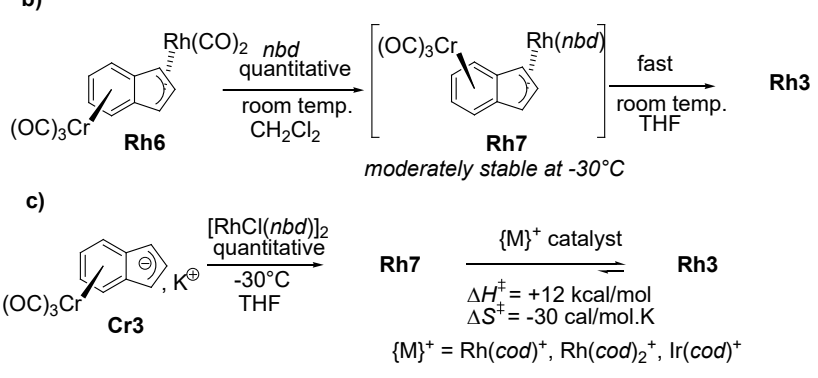

Scheme 1 (one column). (a) The supra and antarafacial binding of cationic transition metal fragments to anionic tricarbonyl $\left(\eta^{5}\right.$-indenyl)chromate $\mathbf{C r} \mathbf{3}$ that yields $\mathbf{R h} \mathbf{3}$ and $\mathbf{R h} \mathbf{2}$, ligand substitution on Rh3 affording Rh4 and Rh5. (b) Rh6 when treated with $n b d$ evolves to $\mathbf{R h} \mathbf{3}$ via metastable $\mathbf{R h} 7$. (c) The drive to syn-faciality: anti-facial $\mathbf{R h} \mathbf{7}$ converts irreversibly to syn-facial $\mathbf{R h} \mathbf{3}$ upon catalytic treatment with Rh and Ir salts.

The work of Ceccon et al. provides further illustrations of the preference for syn-facial bimetallic architectures in indenyl-based $\mathrm{Cr}(\mathrm{CO})_{3}$ complexes (scheme 1). ${ }^{17}$ The reaction of anion $\mathbf{C r} 3$ with $[\mathrm{RhCl}(\operatorname{cod})]_{2}{ }^{18}$ and with $[\mathrm{RhCl}(n b d)]_{2}{ }^{19}$ provided variably single products of opposite facial positioning of the metals on the indenyl ligand, where in anti-facial heterobimetallic compounds 
such as $\mathbf{R h} 2$ the $\mathrm{Rh}(\operatorname{cod})$ unit was seemingly $\eta^{5}$-bonded to the 5 -membered ring. The slow but irreversible conversion of anti-facial $\mathbf{R h} 7$ into syn-facial $\mathbf{R h 3}$ in the presence of catalytic amounts of $[\mathrm{Rh}(n b d)]\left[\mathrm{BF}_{4}\right]^{20}$ with an enthalpy of activation of $c a$. $+12 \mathrm{kcal} / \mathrm{mol}$, counterintuitively suggested that thermodynamic control privileges the syn-facial isomer (scheme 1). ${ }^{21}$ A first theoretical investigation 22 of this unusual "syn-facial tropism" carried out with the EHMO method concluded evasively to the "heterodox" nature of the $\mathrm{Cr}-\mathrm{Rh}$ interaction, owing to the lack of supposedly stabilizing and driving intermetallic bonding orbital interactions. In a new approach of Ceccon's system we focused particularly on the role of electron correlation (assimilated to the close-to-middle distance range component of LDF) in the stabilization of the syn-facial isomers. ${ }^{16 a}$ Energy differences between syn- and anti-facial isomers were calculated at different levels of the WFT (HF vs. SCS-MP2) and DFT (DFT vs. DFT-D2). Calculations at the electron correlation-exempt HF level were found to favor the anti-facial isomers whereas SCSMP2 favored the syn-facial arrangements, inter-fragment correlation energies reaching maximum values for the $\mathrm{Cr}-\mathrm{Rh}$ interaction $(-6 \mathrm{kcal} / \mathrm{mol})$ and for the $\mathrm{Rh}$-bound $\mathrm{CO}$-to-Cr interactions (Figure 2a). ${ }^{16 a}$ Strikingly, ligand-ligand correlation energies across metals were found to contribute significantly to the thermodynamic bias in favor of the syn-facial isomers. Figure $2 \mathrm{a}$ shows the difference in interfragment correlation interaction energies computed for the syn isomer of Rh4 vs. its anti isomer. ${ }^{16 a}$ Worthy to note, the NCI plot ${ }^{\dagger}$ analysis applied to $\mathbf{R h 8}$ (Figure 2) provides an incomplete view of key NCIs; it only reveals the local attractive NCIs build up in the $\mathrm{Cr}-\mathrm{Rh}$ interspace surrounded by a bank of vdW contacts and/or repulsive Pauli interaction. $^{23}$ 

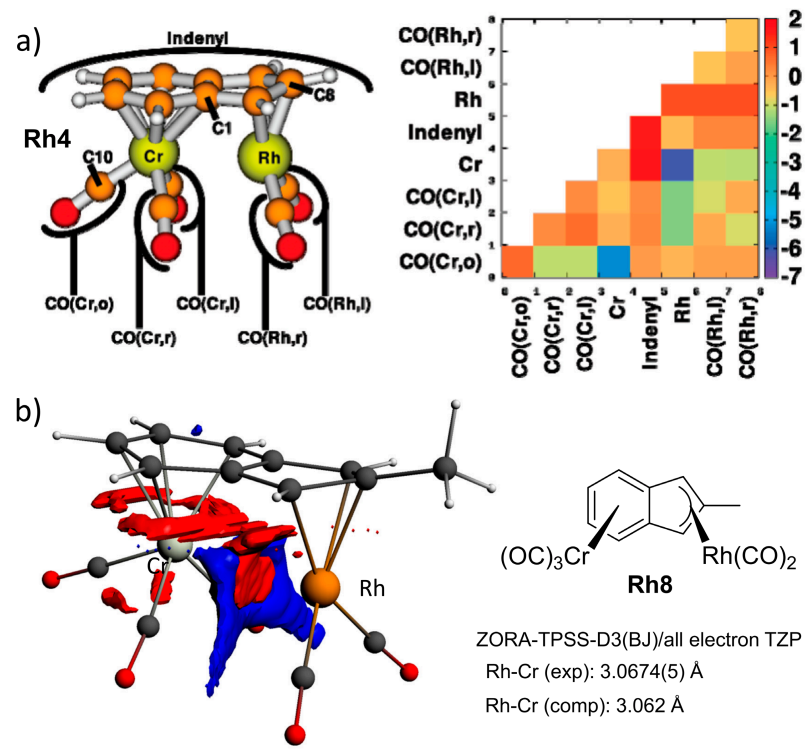

Figure 2. (one column) (a) Differences in intrafragment (diagonal entries) and interfragment (off-diagonal entries) correlation energies $\left(\mathrm{kcal}_{\mathrm{mol}} \mathrm{m}^{-1}\right.$ ) between syn and anti isomers of $\mathbf{R h} \mathbf{4}$ at the SCS-MP2 level (Reprinted with permission from ref. 16a, Copyright 2009 American Chemical Society). (b) The ADF-NCI plot $^{\partial}$ for $\mathbf{R h 8}$ only reveals the local attractive NCIs residing in between the two metal centres.

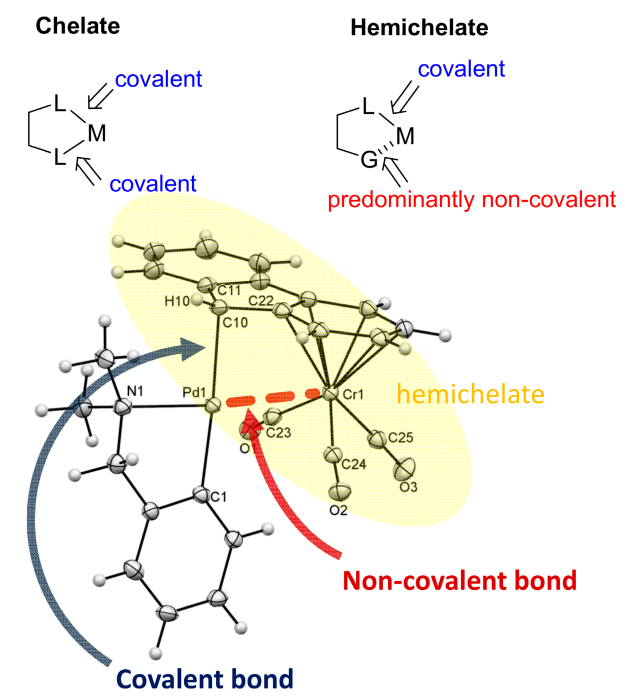

Figure 3 (one column). Description of hemichelation in a tricarbonyl( $\eta^{6}$-fluorenyl)chromium 14 valence electrons $\mathrm{Pd}(\mathrm{II})$ complex. $^{24}$ 
Hemichelation. The term hemichelation proposed in $2013^{1 \mathrm{~b}}$ emerged to fill a gap in the terminology for those peculiar situations where Langmuir's valence electron rule ${ }^{25}$ for late transition metals is violated. If chelation is the entropy-governed ${ }^{26}$ coordination of a ditopic ligand to a metal center, hemichelation is another entropy-favored hetero-bisligation where one of the two sites binds the metal non-covalently (Figure 3).

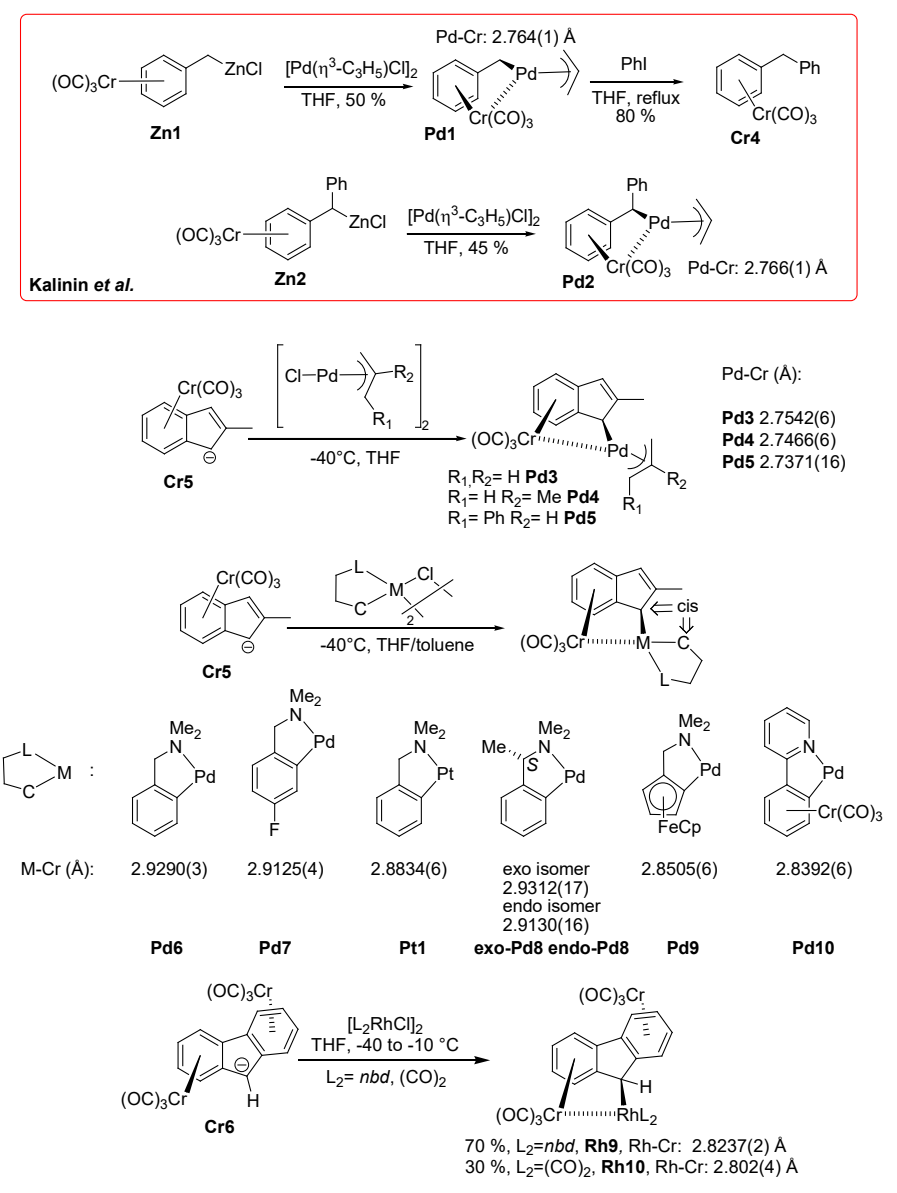

Scheme 2 (one column). The first cases of "hemichelates" Pd1 and Pd2 reported by Kalinin et al. ${ }^{27}$ inspired further syntheses of $\mathrm{Pd}(\mathrm{II}), \mathrm{Pd}(\mathrm{I}), \mathrm{Pt}(\mathrm{II})$ and $\mathrm{Rh}(\mathrm{I})$ cases. ${ }^{1 \mathrm{~b}, 24,28}$

The first cases of hemichelates of Pd(II) appeared in the early 1990's $\mathrm{s}^{27 \mathrm{a}}$ but where not coined as such by Kalinin's group (scheme 2): complexes Pd1 and Pd2 both displayed a synfacial bimetallic arrangement and the hindered rotation of the $\mathrm{Cr}(\mathrm{CO})_{3}$ rotor. 25 years later we proposed to describe Kalinin's compounds as hemichelates of a $\mathrm{Pd}(\mathrm{II})$ center bearing a formal 14 valence electrons configuration. ${ }^{1 b, 28 a}$ 


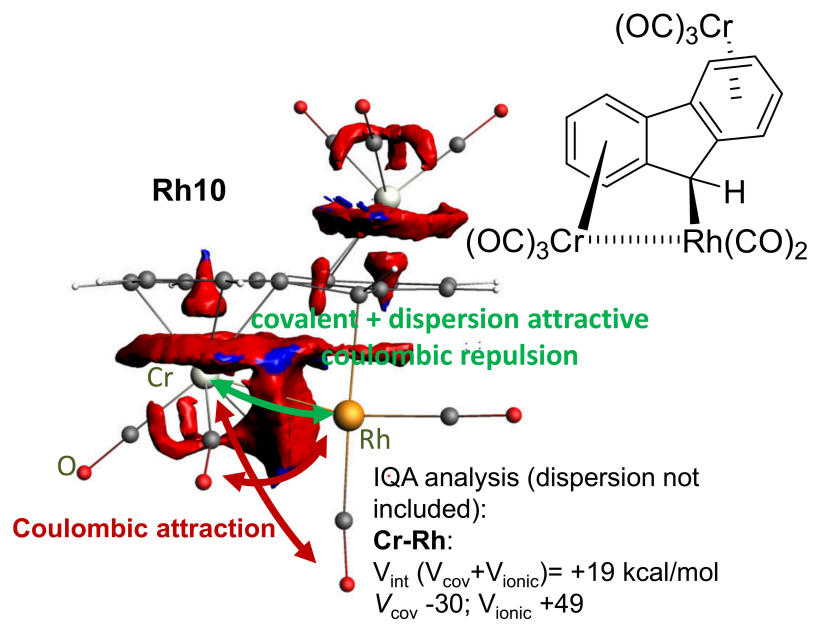

Figure 4 (one column). ADF-NCI $\operatorname{plot}^{\partial}$ and $\mathrm{IQA}^{\neq}$analysis of $\mathbf{R h 1 0}{ }^{28 \mathrm{~b}}$

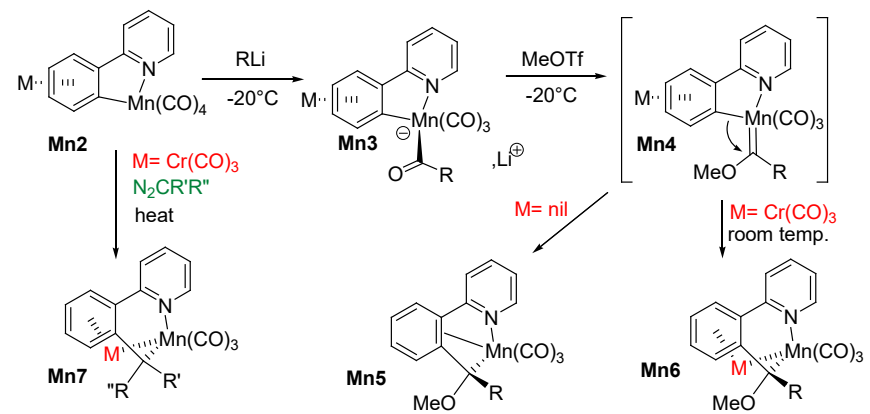

Scheme 3. Hemichelates of $\mathrm{Mn}(\mathrm{I})$ (and $\operatorname{Re}(\mathrm{I}))^{29}$ synthesized by the thermolytic condensation of diazoalkanes with tetracarbonylmetallacycles or by the electrophilic trapping of acylmetallates.

High fluxionality produced by the fast oscillation of the $\left(\eta^{3}\right.$-allyl)Pd moiety between the two benzylic positions of the indenyl was observed in the thermally unstable complexes Pd3-5 (scheme 2). ${ }^{28 a}$ A study of the dynamics of the fluxionality of $\mathbf{P d 3}$ by Sieffert ${ }^{30}$ based on metadynamic-DFT calculations dubbed with QTAIM analysis showed that the fastest motion is the ring slippage of the indenyl ligand with respect to the Pd centre that is coupled with the rotation of the Pd-borne 2-methylallyl ligand, the $\mathrm{Cr}(\mathrm{CO})_{3}$ rotation being significantly slower with a fast rocking motion consisting of transient approaches of carbonyl ligands to the Pd centre. This result corrects the "static view" of a purely NCIs-supported intermetallic interaction, which should be better seen as a dynamic Coulombic- and LDF-dominated 
interaction supported by weak dynamic transient covalent side interactions of the hemichelated metal with neighboring $\mathrm{CO}$ ligands.

Changing the allyl ligand for a $\{\kappa N, \kappa C\}$ heterochelate afforded stable complexes Pd6-10 (scheme 2). Structural fluxionality in solution was established in the case of Pd8 by chemical means applying the Curtin-Hammett principle: $^{1 \mathrm{~b}}$ under acidic treatment planar chiral tricarbonyl[2-methyl- $\left(\eta^{6}\right.$-indene $\left.)\right]$ chromium was released with a temperature-dependent enantiomeric excess.

DFT investigations showed in all cases, e.g. Pd3-10 (scheme 2), that the syn-facial arrangement of the hemichelated metal $\eta^{1}$ bonded to the indenyl ligand, is by $c a$. 10 to 15 $\mathrm{kcal} / \mathrm{mol}$ privileged over any anti-facial isomer. ${ }^{1 \mathrm{~b}, 28 \mathrm{a}}$ Furthermore, it was found that syn-facial hemichelating situations are more stable by $c a .15 \mathrm{kcal} / \mathrm{mol}$ than the alternative syn-facial $\eta^{3}$ bonding of the Pd to the indenyl ligand similar to the Rh and Ir cases reported by Ceccon et al. ${ }^{20}$ If weak covalent interactions were suspected from the short contacts between Cr-bound $\mathrm{CO}$ ligands and the Pd atom in Pd6, they were deemed too weak bridging interactions. ${ }^{28 \mathrm{~d}}$

Two rhodium(I) hemichelates ${ }^{28 b} \mathbf{R h 9}$ and Rh10 (scheme 2, Figure 4) were synthesized by reacting anion $\mathrm{Cr} 7$ with $[\mathrm{RhCl}(n b d)]_{2}$ and $\left[\mathrm{RhCl}(\mathrm{CO})_{2}\right]_{2}$. In both complexes, the $\mathrm{Rh}$ atom is $\eta^{1}$ bonded to the benzylic position and distant by about $2.8 \AA$ from the $\mathrm{Cr}$ center. The latter is ideally positioned in the vacant fourth coordination site of the Rh center. Theoretical analyses ${ }^{28 \mathrm{~b}}$ based on NCI plot, ${ }^{15}$ IQA $^{31}$ and QTAIM ${ }^{32}$ suggested no covalent bond between the two metals, the stability of the two species stemming from attractive coulombic interactions and LDF.

The concept of hemichelation ${ }^{1 \mathrm{~b}}$ also applies to unsaturated octahedral coordination geometry such as that of the Mn(I) center in Mn5-7 (scheme 3). The first examples of such hemichelates were reported in $1998 .{ }^{29 a}$ In those complexes, the $\mathrm{Cr}(\mathrm{CO})_{3}$ moiety non-covalently binds the $6^{\text {th }}$ vacant coordination site at $\mathrm{Mn}(\mathrm{I})$ or $\operatorname{Re}(\mathrm{I})$ centres $(d[\mathrm{Cr}-\mathrm{Mn}(\mathrm{Re})] \sim 3.04 \AA)$. $\operatorname{The} \mathrm{Cr}(\mathrm{CO})_{3}$ rotor displays a slow rotation with a barrier of $c a .+15 \mathrm{kcal} / \mathrm{mol}^{33}$ The folded rigid 6-membered metallacycle and the overall cluttering around the two metals confer an outstanding thermal stability and air tolerance to these 16 electron $\mathrm{Mn}(\mathrm{I})$ (or Re(I)) complexes. ${ }^{34}$ A DFT-D1 theoretical study ${ }^{34}$ described the nature of the interaction between the $\operatorname{Cr}(0)$ center and the $\operatorname{Mn}(\mathrm{I})$ 
as a mutually compensating combination of a $\mathrm{Cr} \rightarrow \mathrm{Mn}$ donor-acceptor 3-orbital 4-electron interactions and its $\mathrm{Mn} \rightarrow \mathrm{Cr}$ back-bonding counterpart supported by LDF and electron correlation. A fictitious anti-facial isomer was found to be less stable by $c a$. $15 \mathrm{kcal} / \mathrm{mol}$ than its syn-facial counterpart.
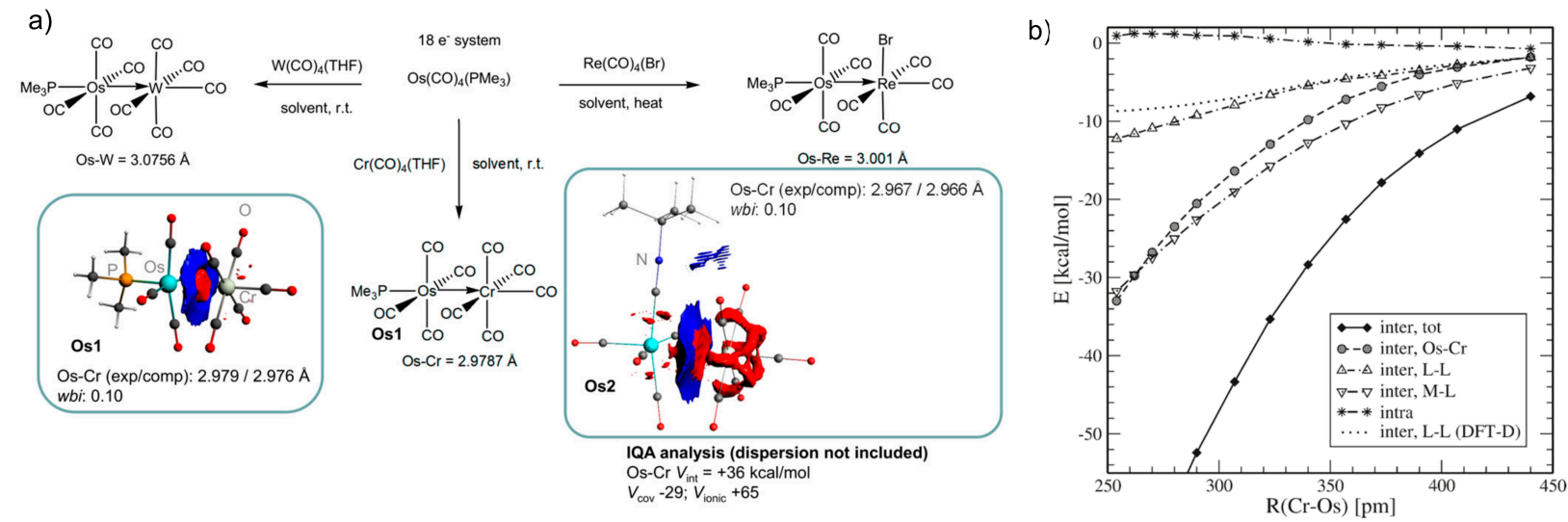

Figure 5 (two columns). (a) Pomeroy's donor-acceptor complexes are cohesive thanks to electron correlation and $\mathrm{LDF}^{16 \mathrm{~b}}$, the intermetallic covalent component alone being too weak to ensure cohesion. (b) Correlation energy contributions (inter- and intrafragment) to the dissociation energy (i.e., the HF energy is omitted) along the dissociation path for Os1 at the SCS-MP2/ level. The interligand LDF (DFT-D) contribution is also given (Reprinted with permission from ref. ${ }^{16 \mathrm{~b}}$, Copyright 2010 American Chemical Society).

Unsupported Metal Donor-to-Metal Acceptor Complexes. We have shown that the intramolecular cohesion of a synfacial complex does not only rely on localized metal-centered interactions. LDF-based inter-ligand interactions across the metals as well as metal-ligand interactions at a distance contribute significantly to cohesion. Evaluating the validity of these conclusions with compounds devoid of a bridging ligand was essential. This endeavor stressed that a conventional metal-centered analysis of bonding limited to the primary coordination sphere was insufficient and misleading. Only the determination of the balance existing between all attractive and repulsive metal-ligand, intermetallic and interligand interactions in an unsupported metal-metal donor-acceptor (D-A) complexes could reveal the origin of molecular cohesion. The first type of unsupported metal-metal interaction to be addressed was that of stable and solution-persistent Lewis-type metal-metal donor-acceptor (D-A) pairs. ${ }^{16 \mathrm{~b}}$ A large 
choice of persistent and temperature-stable complexes were available where an Os-centred moiety acted as a 2 electron donor in a Lewis pair (Figure 5a) formed by solvent displacement from solvato complexes of $\mathrm{W}, \mathrm{Cr}$ or $\mathrm{Mn}$ acting as Lewis acceptors. ${ }^{35}$ The predominance of an intermetallic "dative bond" was claimed in numerous cases based on the conclusions drawn from the HF analysis by Nakatsuji et al of one prototypical model. ${ }^{36}$. Our study carried out with DFT$\mathrm{D}$ and WFT methods invalidated Nakatsuji's conclusions though. The low values of intermetallic Wiberg bond index and the weak accumulation of charge densities around the metals were clear symptoms of a very weak covalent metal-metal interaction. Semi-local DFT approximations, the double-hybrid B2PLYP functional as well as the dispersion-corrected DFT methods (TPSS-D2 and B2PLYP-D2) and the WFT-based SCS-MP2 established the overwhelming contribution of both intermetallic and interligand LDF in the Lewis pair's cohesion (Figure 5b). ${ }^{16 \mathrm{~b}} \mathrm{NCI}$ plots showed local attractive interaction domains between metal centers, like in Os1 and in the $t$-BuN=C complex Os2 (Figure 5a). ${ }^{23}$ 

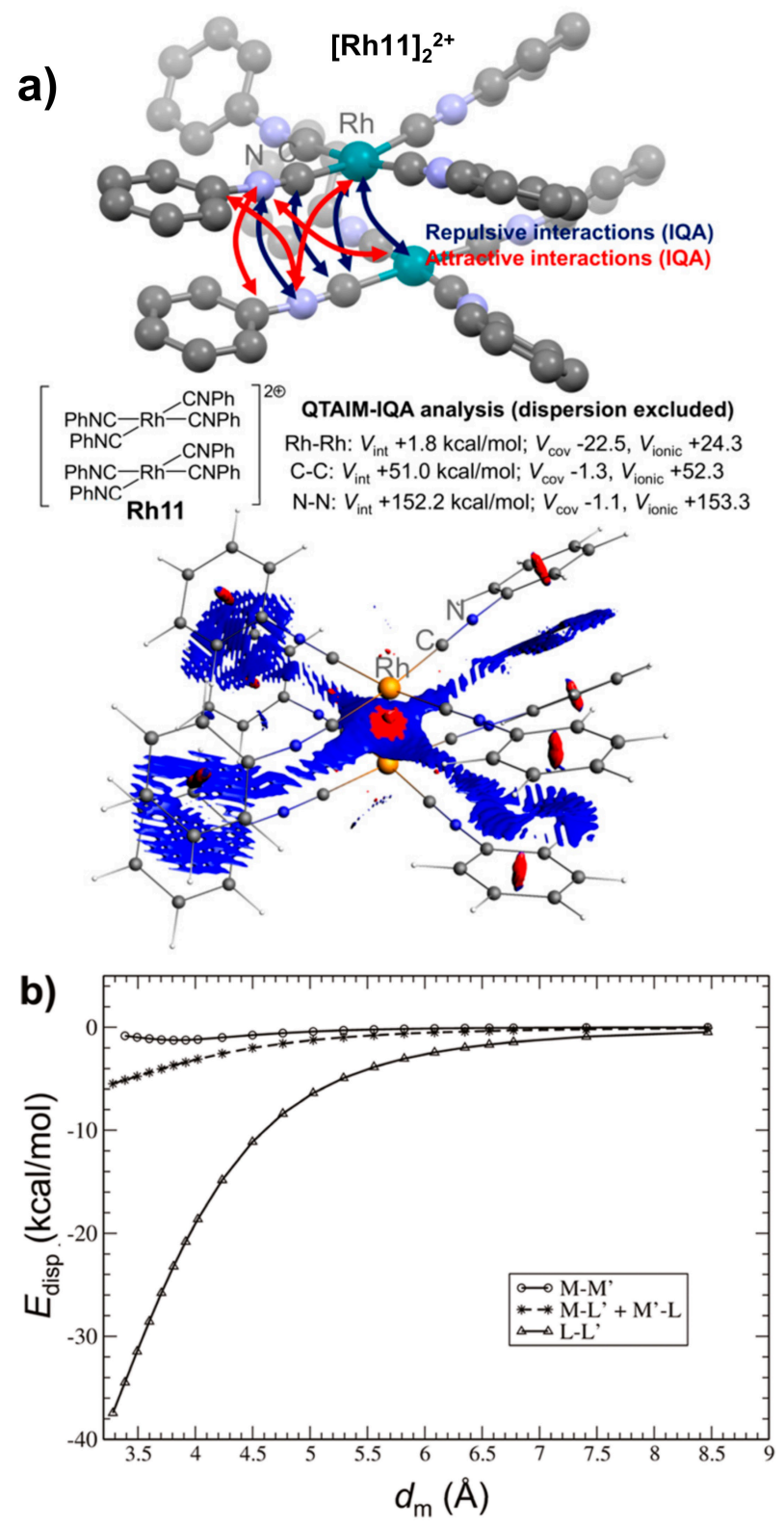

Figure 6 (one column). (a) Analysis of Dicationic bis[tetrakis(phenylisonitrile)rhodium(I)] $[\mathbf{R h 1 1}]_{2}{ }^{2+}$ by $\mathrm{IQA}^{\neq}$and ADF-NCI plot $^{\partial}$ : the former shows the major repulsive Coulombic component of the Rh-Rh, C-C and N-N interactions, the latter outlines the correlation-based Rh$\mathrm{Rh}$ attraction. (b) LDF contributions (TPSS-D3) of the metal atoms and ligand fragments to the dissociation energy of $[\mathbf{R h} 11]_{2}{ }^{2+}$ (Reprinted with permission from ref. ${ }^{\text {la }}$, Copyright 2011 American Chemical Society).

When LDF beats Coulombic Repulsion. To probe the stabilizing contribution of LDF from extended ligands we chose to address the typical case of square planar monocationic tetrakis(alkyl or arylisonitrile)Rh(I) complexes known for their propensity to form dicationic 
dimers and other oligomeric polycations when dissolved in polar solvents or when crystallized. ${ }^{37}$ Since in most reported cases $\mathrm{Rh}(\mathrm{I})-\mathrm{Rh}(\mathrm{I})$ dimers displayed an average metal-metal distance of $c a$. $3.1 \AA$ conjectures fueled the hypothesis of a special metal-metal " $d^{8}-d^{8}$ " interaction ${ }^{38}$ acting as the central driving force of the aggregation. The prototypical $\left[(\mathrm{PhCN})_{4} \mathrm{Rh}\right]^{+}\left([\mathbf{R h} \mathbf{1 1}]^{+}\right)$ complex $^{39}$ was investigated both experimentally and theoretically ${ }^{1 \mathrm{a}}$ using DFT-D3 and WFTbased (SCS-MP2) methods (Figure 6a). The salient result of our theoretical study was that those dicationic dimers are stable in polar solvents mostly due to interligand LDF that overruns Coulombic repulsion. The IQA ${ }^{31 a}$ analysis $^{31 b}$ shown in Figure 6a illustrates the entanglement of attractive and repulsive interligand Coulombic interactions. Various DFT investigations of the dissociation of dimers revealed that the formation of stable dimers required the use of LDFcorrected functionals combined to a continuum screening solvation model and concluded to a large contribution of the LDF correction to the binding energy ( $c a .-43 \mathrm{kcal} / \mathrm{mol}$, Figure $6 \mathrm{~b}){ }^{1 \mathrm{a}}$ The influence of the LDF correction to native functionals was particularly visible from the "compactization" of the dimer structures, the aromatic isonitrile ligands enhancing their mutual attractive interactions (Figure 6b). The calculated Gibbs free energy of $-7.3 \mathrm{kcal} / \mathrm{mol}$ for the formation of $[\mathbf{R h 1 1}]_{2}{ }^{2+}$ compared well with the experimental value of $\sim-2 \mathrm{kcal} / \mathrm{mol}$ inferred from experiment. ${ }^{39}$ SCS-MP2 calculations revealed that $d^{8}-d^{8}$ valence correlation contributes by about $-3.5 \mathrm{kcal} / \mathrm{mol}$ to binding near the equilibrium distance (core and core-valence correlation between the metals adding $-1.3 \mathrm{kcal} / \mathrm{mol}$ to binding), which represents only $10-15 \%$ of the total interaction correlation energy. This result rules out the driving role of $d^{8}-d^{8}$ interactions that deceivingly appear as dominant in the NCI plot $^{\dagger}$ analysis (Figure 6a).

\section{Reactivity.}

NCIs play a great role in the stability of molecular aggregates. In reactions in solution, a transition state (TS) may be preceded by the reversible formation of $\mathrm{vdW}$ molecular aggregates of the reactants, also known as reactant complexes (RCs). The latter constitute a peculiar form of the assembly of reactants preparing to the bond breaking/forming event occurring at the nearest low lying TS. ${ }^{10 a, 40}$ By virtue of their flexibility, NCIs allow the optimal adjustment of the RCs' geometry and electronic structure in their way to TSs. Among all the components of NCIs involved in chemical reactions, local electric fields are well known powerful players in the 
polarization and reorganization of bonds. ${ }^{41}$ Therefore, if NCIs take a major role in the polarization of bonds in the "reactive site" of a RC, thus preparing it for further chemical transformation, describing NCIs qualitatively and quantitively at a reactive site is the key to controlling chemical reactivity.

The investigations by Bistoni and Neese ${ }^{42}$ of the role of LDF in the stabilization of socalled $\mathrm{C}-\mathrm{H}$....metal agostic interactions turned our attention to similar intermediates that are crucial RCs in the so-called AMLA/CMD mechanism ${ }^{43}$ relevant to $\mathrm{C}-\mathrm{H}$ bond functionalization catalysis. $^{44}$
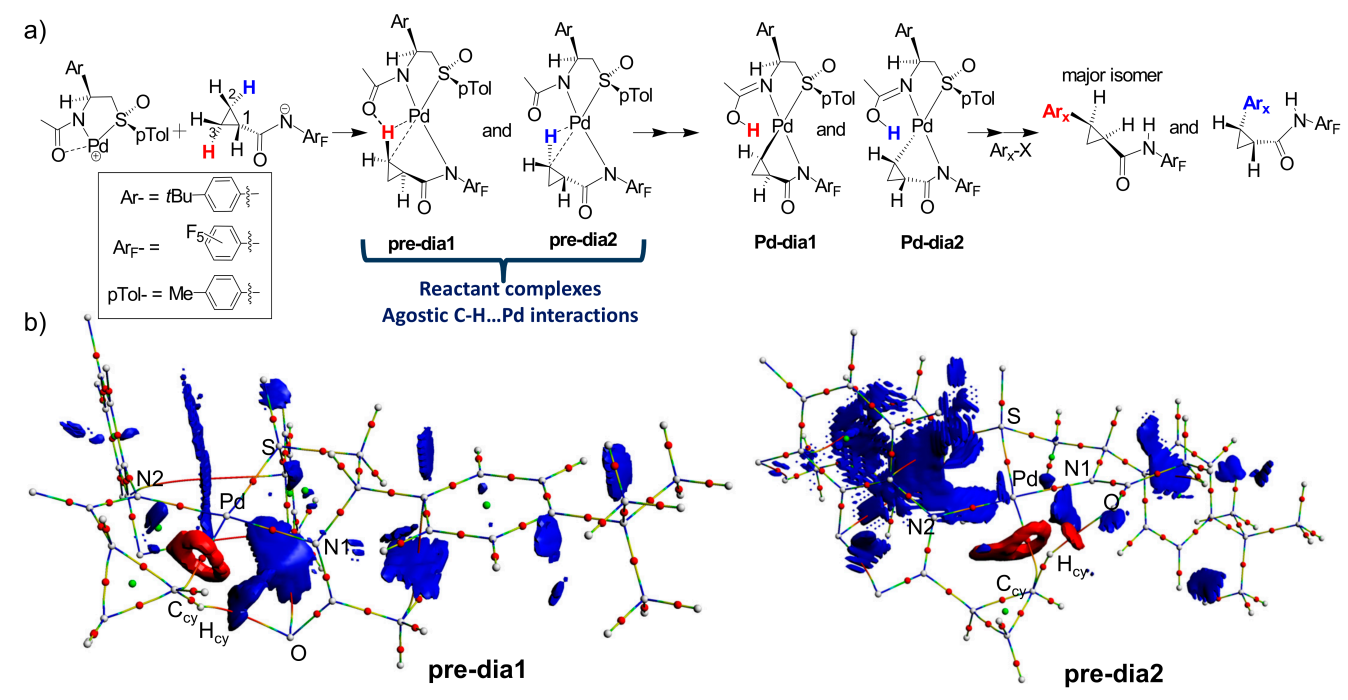

Figure 7. The agostic pre-dia1 and pre-dia 2 intermediates ${ }^{45}$ drawn as a diagrams of the $(3,+1)$ ring (green dots) and $(3,-1)$ bond critical points (red dots) and paths, display NCI plot $^{\partial}$ isosurfaces of attractive domains (red-colored) centered at bond critical points that prefigure the base-assisted carbopalladation reaction. Attractive rings suggest NCIs-supported covalent $\sigma$-C$\mathrm{H}-\mathrm{Pd}$ agostic bonds.

The buildup of attractive NCI plot isosurfaces in key agostic C-H...Pd intermediates of the enantioselective base-assisted palladation of a C-H bond in cyclopropanes ${ }^{45}$ (Figure 7) suggested that the ensuing concerted base-assisted proton-transfer /carbometallation step might well be somewhat "NCI-coded". This hypothesis prompted us to start a deeper scrutiny of the interplay of local NCIs in AMLA/CMD-based cyclometallations. Our early investigations relied on a combination of state-of-the-art tools free of issues related to BSSE: DFT-D ${ }^{3 b}$ and QTAIM$\mathrm{IQA}^{31 \mathrm{a}}$ analysis were privileged for preliminary evaluations of interactions, NCI plot $^{15, \dagger}$ was used 
for swift diagnostics of existing NCIs signatures in the reactive site of a given RC. The accurate analysis of the partitioning of NCI energy contributions was eventually achieved by the LED/DLPNO-CCSD(T) method. ${ }^{2}$

\section{The NCI-inclusive Exploration of Reactivity in the Base-Assisted Cyclometallation}

of Aromatics. We undertook a systematic investigation of the base-assisted cyclometallation reaction geared by the AMLA/CMD mechanism that was largely studied with complexes of 4-5d metals. Our far reaching goal was to devise a predictive methodology that could help engineering its applications in homogenous $\mathrm{C}-\mathrm{H}$ bond functionalization catalysis with challenging $3 d$ transition metals such as $\mathrm{Ni}$ and $\mathrm{Co}^{2}$

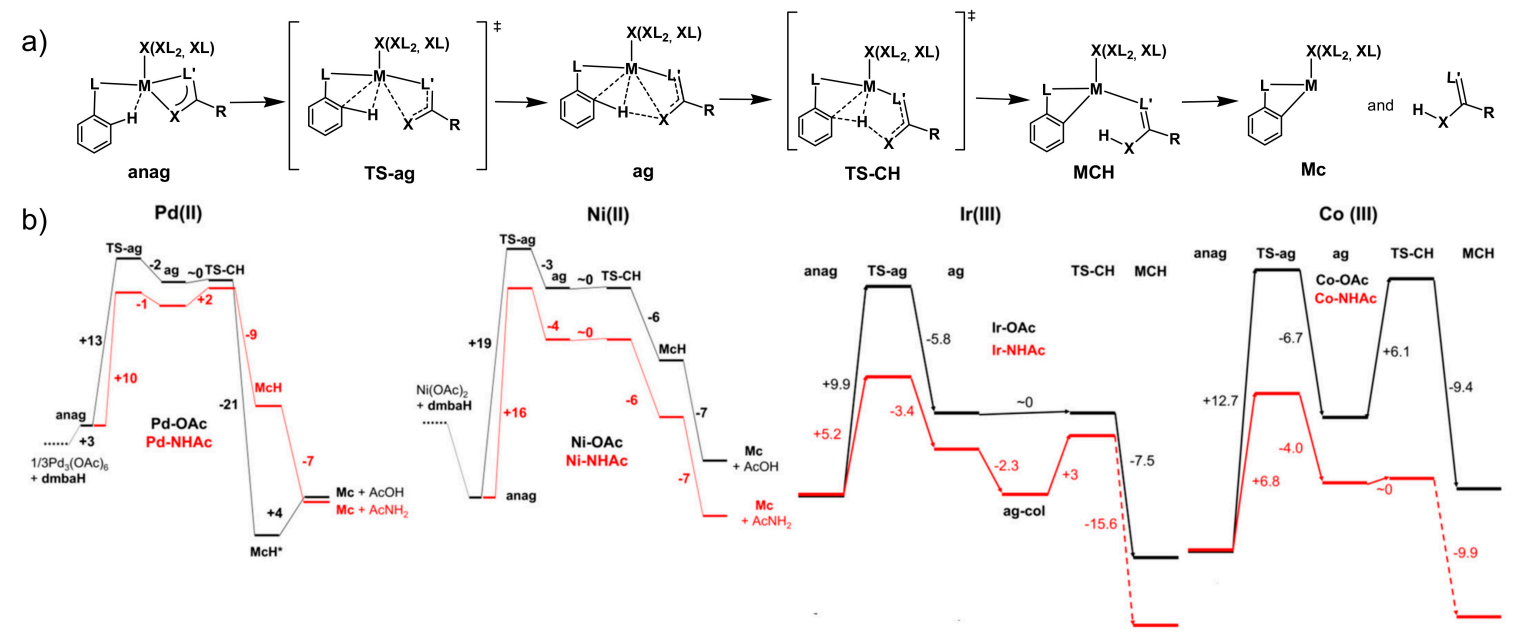

Figure 8. (a) The simplified AMLA/CMD mechanism. (b) (COSMO)-DFT-D energy profiles of the cyclo-palladation/nickelation ${ }^{2 a}$ of $N, N$-dimethylbenzylamine and of the cycloiridation/cobaltation ${ }^{2 \mathrm{~b}}$ of 2-phenylpyridine using $\mathrm{AcO}^{-}$(black lines) and $\mathrm{AcNH}^{-}$(red lines) as bases. $^{2}$

The AMLA/CMD mechanism entails three steps (Figure 8). The first step is the coordination of the "directing group" acting as a ligand giving rise to a so-called "anagostic" intermediate, noted anag where the $\mathrm{C}-\mathrm{H}$ bond to be activated is generally positioned at $c a$. 2.7$3.2 \AA$ from the metal centre with a weak interaction of the latter with the carbon of the $\mathrm{C}-\mathrm{H}$ motif. The second step is the decoordination of one of the $\kappa^{2}$-metal-bound carboxy-base leading via transition state TS-ag to the formation of an agostic intermediate ag. In the latter the C-H 
bond attractively interacts with the metal centre located within a multipolar environment where the positioning of the $\mathrm{C}-\mathrm{H}$ bond close to the vicinal cis base prefigures the following $\mathrm{C}-\mathrm{H}$ bond cleavage. The third step is the $\mathrm{C}-\mathrm{H}$ bond activation that consists of the concerted metallation of the reactive carbanionic center and a proton transfer to the nearby base in ag via transition state TS-CH that leads to $\mathbf{M c H}$. This mechanism was instrumental to probe the question of NCIs' influence over the rate determining step for $\mathrm{Ni}$ and $\mathrm{Pd}(\mathrm{II})$ as well as for Co and $\operatorname{Ir}(\mathrm{III})$ centres. $^{2}$ If intermediate ag is still to date an elusive "mind view", the hypothesis of its pivotal role has gained strength in a recent report on the time-resolved IR spectroscopic ${ }^{46}$ tracking of short-lived species produced by protonation of a manganacycle.

The striking similitude of the NCI plots of the intermediates of the investigated $\mathrm{Ni}, \mathrm{Pd}$, Co and Ir-based CMD mechanisms ${ }^{2}$ (Figures 9 and 10, cf. Supp. Mat.) outlines features independent from the nature of the metal and of the level of theory used that are: ${ }^{2}$

a) the rate limiting step of the cyclometallation reaction is the formation of the agostic intermediate ag from anag via TS-ag.

b) the transition from anag to ag via TS-ag is highly influenced by the Coulombic repulsion pre-existing in anag between the $\mathrm{C}_{\mathrm{Ar}}-\mathrm{H}$ bond and the metal centre.

c) the carbometallation process that transforms ag into $\mathbf{M c H}$ via $\mathbf{T S}-\mathbf{C H}$ requires a barrier of activation lower than $\sim 6 \mathrm{kcal} / \mathrm{mol}$ in most cases,

d) NCI plot analysis of ag contains attractive isosurfaces that prefigure the transformation occurring at TS-CH. 


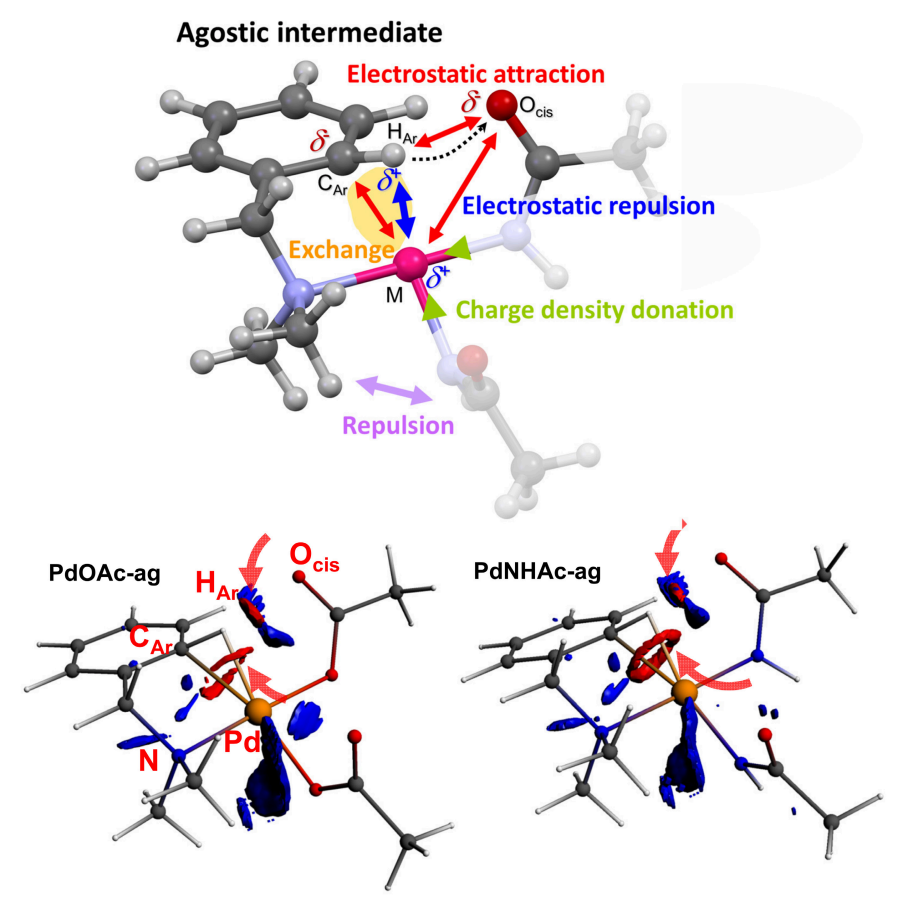

Figure 9 Top: Interactions at play in the key ag agostic intermediate of the AMLA/CMD Ni/Pd cyclometallation. Bottom: ADF-NCI plots ${ }^{\partial}$ in two $\mathrm{Pd}(\mathrm{II})$ agostic intermediates revealing the attractive interactions (red colored isosurfaces) of the $\mathrm{C}-\mathrm{H}$ bond with the Pd-bound auxiliary base $\left(\mathrm{AcO}^{-}\right.$or $\left.\mathrm{AcNH}^{-}\right)$and the metal. ${ }^{2 b}$ 


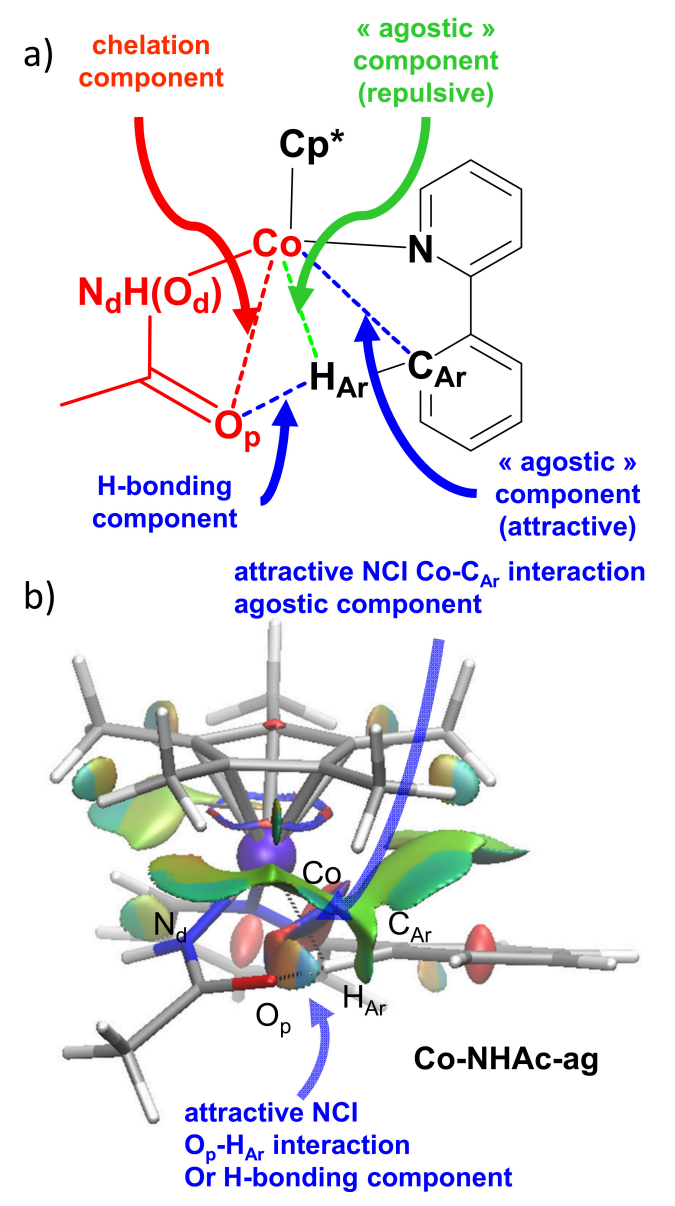

Figure 10 Top: interactions at play in the key agostic intermediate of the AMLA/CMD cyclocobaltation. ${ }^{2 b}$ Bottom: NCI plot ${ }^{\ddagger}$ drawing in an agostic intermediate, revealing attractive interactions of $\mathrm{C}_{\mathrm{Ar}}$ and $\mathrm{H}_{\mathrm{Ar}}$ of the $\mathrm{C}-\mathrm{H}$ bond with the metal centre $\mathrm{Co}$ and the auxiliary base via $\mathrm{O}_{\mathrm{p}}$.

Our analysis of the mechanism of cyclopalladation and cyclonickelation ${ }^{2 a}$ pointed out the crucial role played by electrostatic interactions. Quite readily figured was the sensitivity of the anag $\rightarrow$ [TS-ag] $^{\neq}$energy barriers to the Bader charge borne by the metal centre, which is higher with $3 d$ metals than with $4-5 d$ ones. This slightly higher charge causes an increase of the C-H...metal repulsion resulting in an increase of the anag $\rightarrow[\text { TS-ag }]^{\ddagger}$ barrier of $c a .6 \mathrm{kcal} / \mathrm{mol}$ in the case of the Ni system (as compared to $\mathrm{Pd}$ ) ${ }^{2 \mathrm{a}}$ and only $2 \mathrm{kcal} / \mathrm{mol}$ in the case of the Co system (as compared to $\mathrm{Ir}){ }^{2 \mathrm{~b}}$ regardless of the assisting base.

The formation of an agostic intermediate $\mathbf{a g}^{\mathbf{4 7}}$ is therefore not only crucial but must occur within a proper multipolar environment around the $\mathrm{C}-\mathrm{H}$ bond. This environment was assessed 
from Bader charges and from NCI plot isosurfaces related to the reactive site of ag: all NCI plots indicated the presence of attractive domains in the $\mathrm{C}-\mathrm{H}$... base and $\mathrm{C}-\mathrm{H}$... metal interspace at the key locations (generally at bond critical points) where major bond changes are to occur.

Substitution of the acetate base for the more basic acetamidate lowers the activation barrier (Figure 7) of the rate determining step anag $\rightarrow[\text { TS-ag }]^{\neq} \rightarrow \mathbf{a g}$ by $2-3 \mathrm{kcal} / \mathrm{mol}$ with $\mathrm{Pd}$ and $\mathrm{Ni}^{2 \mathrm{a}}$ systems and by $50 \%$ with Ir and Co ones. ${ }^{2 b}$ The improvement of the cyclometallation reaction expressed by lower barriers with acetamidate as base in all cases stems from 1) a lower propensity of the metal-bound base to maintain the residual chelation with the metal centre and 2) the decrease of the positive charge at the metal centre that reduces the repulsive component of the "anagostic" and the agostic interactions in anag and ag respectively.

In the case of $\mathrm{Co}$, the use of acetamidate as base cancels the $c a .6 \mathrm{kcal} / \mathrm{mol}$ high (DFT-D) CoOAc-ag $\rightarrow[\text { CoOAc-TS-CH }]^{\neq}$barrier encountered with $\mathrm{AcO}^{-}$. With the latter base, CoOAcag is placed in an energy well where its back conversion to CoOAc-anag is virtually as probable as its conversion into CoOAc-MCH. Experimentally, the cyclocobaltation of 2-phenylpyridine yields about 8-9 times less cobaltacycle when $\mathrm{NaOAc}$ is used as a base than when $\mathrm{LiN}(\mathrm{H}) \mathrm{Ac}$ is used. $^{2 b}$

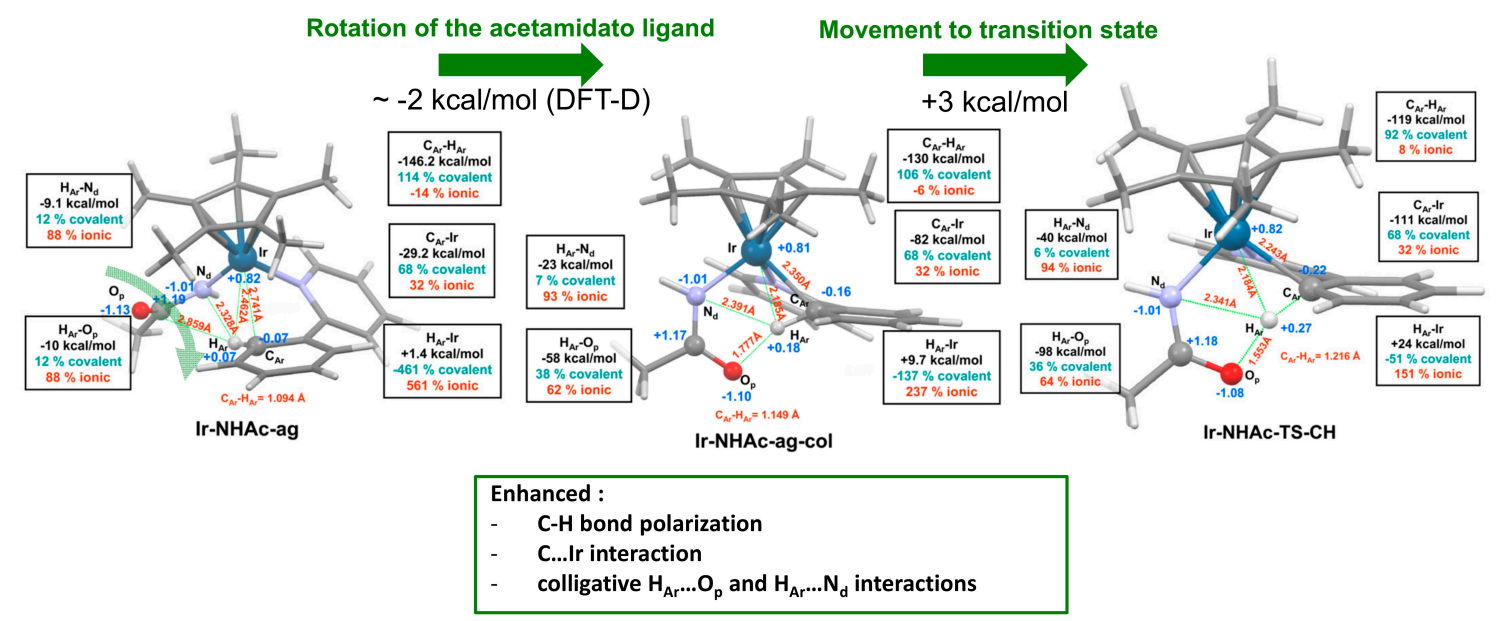

Figure 11. The AMLA/CMD mechanism of the cycloiridation of 2-phenylpyridine: the alignmet of the acetamidato ligand in ag with the $\mathrm{C}-\mathrm{H}$ bond triggers its polarization and preparation to pass the transition state. ${ }^{2 b}$ 
Quite illustrative of the specificity of the AMLA/CMD mechanism is the importance of the positioning of the metal-bound base for the optimal polarization of the $\mathrm{C}_{\mathrm{Ar}}-\mathrm{H}$ bond in IrNHAc system at the stage of the agostic intermediate IrNHAc-ag. Figure 11 displays the structures of IrNHAc-ag and its rotamer IrNHAc-ag-col where the $\mathrm{C}_{\mathrm{Ar}}-\mathrm{H}_{\mathrm{Ar}}-\mathrm{O}_{\mathrm{p}}$ centres are quasi co-linear. Bader charges and IQA ${ }^{31 a}$ analysis are particularly instructive of the interplay of the atomic centres of the reaction site in conditioning the evolution of this "agostic" transient. The specific $\mathrm{C}_{\mathrm{Ar}}-\mathrm{H}_{\mathrm{Ar}}-\mathrm{O}_{\mathrm{p}}$ alignment lowers the energy by $c a .2 \mathrm{kcal} / \mathrm{mol}$ and causes tremendous changes at the $\mathrm{C}_{\mathrm{Ar}}-\mathrm{H}_{\mathrm{Ar}}$ bond. As the acetamidate ligand rotates, the $\mathrm{C}_{\mathrm{Ar}}-\mathrm{H}_{\mathrm{Ar}}$ bond undergoes the polarization decisive to its cleavage. The $\mathrm{H}_{\mathrm{Ar}}$ atom more than doubles its Bader charge from +0.07 to +0.18 (Figure 10) and becomes colligated to two Lewis basic sites belonging to the acetamidate, i.e. $\mathrm{O}_{\mathrm{p}}$ and $\mathrm{N}_{\mathrm{d}}$. The negative charge of $\mathrm{C}_{\mathrm{Ar}}$ rises together with its attractive interaction with the Ir centre. This situation shows that minor steric changes in the vicinity of the "reaction site" might impact the very feasibility of the proton transfer step owing to conformational restrictions.

\section{Adressing Chemoselectivity from the Electron Density Topology in Reactant Complexes.}

Several analytical tools derived from the QTAIM ${ }^{32}$ can qualitatively and quantitatively address the relevance of NCIs within RCs. NCI plot ${ }^{15}, \mathrm{IQA}^{31 \mathrm{a}}, \mathrm{IGM}^{48}$ and $\mathrm{IBSI}^{49}$ provide qualitative and quantitative levers to address local NCIs at the key "reactant complex" stage (Figure 12a). These new tools represent a promising arsenal to address the question of reactivity analysis and prediction.

a)

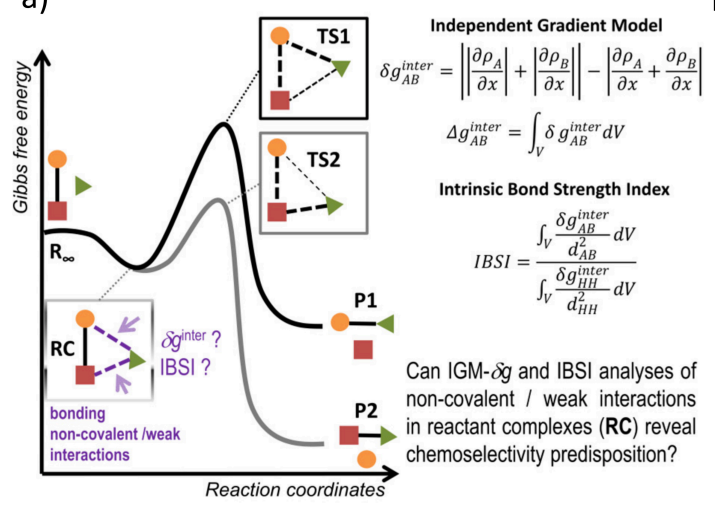

b)

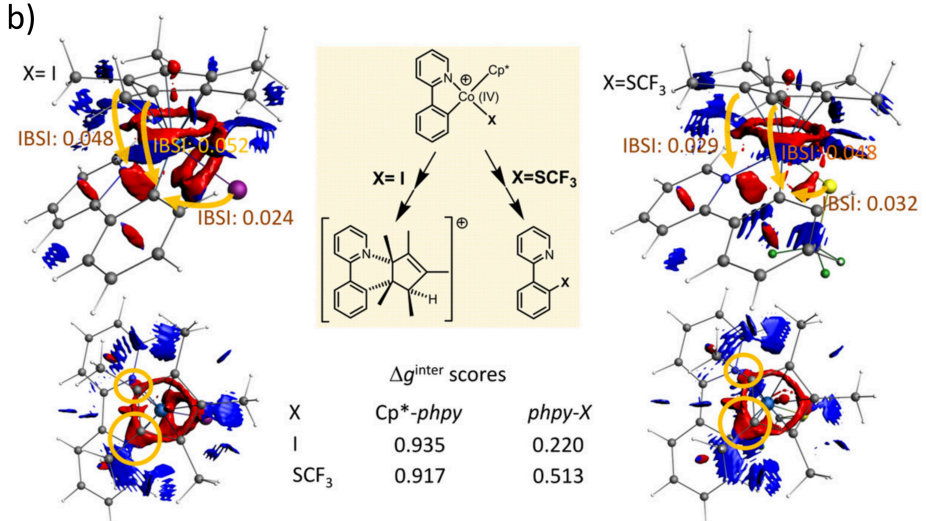

Figure 12. a) IGM and IBSI analyses ${ }^{\#, 48-49}$ of weak interactions and NCIs in a RC as an expedient to rationalize chemoselectivity towards products (P1 and P2): A and B are any user- 
defined fragments of the considered RC. b) ADF-NCI plots ${ }^{\partial}$ (side and top views), IBSI and IGM analyses $^{\#}$ of two 2-phenylpyridine-derived Co(IV) metallacycles differing by the nature of ligand $\mathrm{X}\left(\mathrm{X}=\mathrm{I}^{50}\right.$ or $\left.\mathrm{SCF}_{3}{ }^{51}\right)$ determines the fate of the complex. IBSI and $\Delta g^{\text {inter }}$ analyses of user-defined interatomic and interfragment interactions show a higher $\mathrm{C}^{*}$ - $p h p y$ interaction when $\mathrm{X}=\mathrm{I}$ and a higher phpy-X interaction when $\mathrm{X}=\mathrm{SCF}_{3}$.

One recent example of such application relates to the fate of cobaltacycles of Co(III) when oxidized into formal Co(IV) species (Figure 12b). ${ }^{50}$ This oxidation is essential ${ }^{51}$ particularly in the pivotal step of extrusion of the organic product in the $\mathrm{Cp} * \mathrm{Co}$ (III) mediated $\mathrm{C}-\mathrm{H}$ bond functionalization catalysis, ${ }^{44}$ which requires oxidizers as co-catalysts. Depending on the nature of the X ligand (Figure 12b), the short-lived Co(IV) 2-phenylpyridine-based transient ${ }^{50}$ can either undergo the reductive elimination of $\mathrm{X}-p h p y^{51}$ or the cyclocondensation ${ }^{2 \mathrm{~b}}$ of the $\mathrm{Cp}^{*}$ ligand with the phpy ligand that causes the undesired collapse of the catalyst. In this case, the $\mathrm{Co}(\mathrm{IV})$ metallacycle can reasonably be considered as a typical reactant complex at a reactional cross-road offering two possible evolutions. NCI plots of the latter revealed the existence of unusual attractive isosurface outgrowths below the plane of the $\mathrm{Cp}^{*}$ that suggest specific attractive interactions between carbons of the $\mathrm{Cp}^{*}$ ligand and the $\mathrm{N}$ and carbanionic $\mathrm{C}$ atom of phpy responsible for the the phpy-Cp* cyclocondensation. Similarly, other NCI attractive isosurfaces between the phpy and $\mathrm{X}$ ligands suggested that the $\mathrm{Co}(\mathrm{IV})$ metallacycle is also intrinsically prepared for the $\mathrm{X}-p h p y^{50}$ reductive elimination pathway. Interatomic IBSI and interfragment IGM- $\Delta g^{\text {inter }}$ scores $^{\#}$ substantiated clearly the intuitive information provided by NCI plot isosurfaces by a quantitative measure of the latent strengths of those non-covalent interactions existing between the carbon centres of the $\mathrm{Cp}^{*}$ and the phpy ligand. Both IBSI and IGM- $\Delta g^{\text {inter }}$ values were consistent with experimental observations, i.e. that the cyclocondensation of $\mathrm{Cp}^{*}$ with phpy is more favorable when $\mathrm{X}=\mathrm{I}$, while the reductive elimination pathway relevant to the $\mathrm{C}-\mathrm{H}$ bond thiolation catalysis is favored when $\mathrm{X}=\mathrm{SCF}_{3} .{ }^{50}$

\section{Conclusion.}

Noncovalent interactions play a central role in molecular cohesion as well as in the reactivity of organometallic systems in various ways. Our studies have shown that NCIs can stabilize 
electron unsaturated metal centres in species that were long considered elusive, such as the persistent T-shaped 14-electron Pd hemichelates with NCIs anchors consisting of a $\pi$-bonded $\mathrm{Cr}(\mathrm{CO})_{3}$ moiety. A shift of paradigm from the classical Chatt-Duncanson/Lewis metal-centered approach of bonding to the account of all attractive and repulsive interactions by means of DFTD and WFT was nevertheless required to establish the contribution of NCIs to cohesion in molecular aggregates. ${ }^{42}$ If the NCI plot tool is useful in a preliminary approach to reveal short range NCIs, full scale WFT analysis of molecular cohesion should be privileged, for NCIs operate in Werner's ${ }^{52}$ secondary coordination sphere as well as in the primary. NCIs have a full-fledged role in reactivity that can be traced by ab initio and DFT-D methods like shown for the AMLA/CMD cyclometallation. The new IBSI and IGM descriptors applied to the analysis of NCIs are promising tools to address the issue of chemoselectivity. The hypothesis that the fate of key RCs such as the above-mentioned Co(IV) metallacycles might be predictable from those descriptors, although enticing, requires further evaluations. Such hypothesis, if validated and generalized to other metal-promoted reactions, could lay the basis of a new predictive framework for the engineering of catalysts.

Available Supporting Information. Cartesian coordinates in the .xyz format, high resolution NCI plots, energies and computational details for Rh10, Os2 and $[\mathbf{R h} 11]_{2}{ }^{2+}$.

\section{AUTHOR INFORMATION}

\section{Corresponding Author}

* Dr Jean-Pierre Djukic, E-mail: djukic@unistra.fr

\section{Author Contributions}

The manuscript was written through contributions of all authors. All authors have given approval to the final version of the manuscript. The authors contributed equally.

The authors declare no competing financial interests. 


\section{Funding Sources}

The Centre National de la Recherche Scientifique

The University of Strasbourg

The Alexander von Humboldt foundation

The Agence Nationale de la Recherche

The LABEX Chimie des Systèmes Complexes

\section{Notes}

$\dagger$ The NCI plot method of real space detection and visualization of local short range NCIs, i.e. between spatially proximal molecular fragments or atoms, is based on the electron density $\rho$ and its derivatives. This region analysis provides intuitive three-dimensional isosurface representations of local Pauli repulsion and steric clashes, vdW interactions, and other local attractive NCIs. NCI plot is based on the strong dependence of the reduced density gradient $s$ on the signed value of the density $\lambda_{2} \rho$, which allows, by the choice of an appropriate cutoff value for $s$, to distinguish NCIs from covalent interactions and to sort the former into attractive and nonbonded (van der Waals) or repulsive (Pauli) classes depending on the sign of the second electron-density Hessian eigenvalue $\lambda_{2}$. The sign of the latter is positive for non-bonded and repulsive interactions, and negative for attractive NCIs.

${ }^{\partial}$ NCIs are materialized by reduced density gradient isosurfaces (cut-off value $s=0.5$ a.u., $\rho=$ 0.02 a.u.) colored according to the sign of the signed density, i.e. in red for attractive domains and in blue for repulsive and non-bonding domains.

${ }^{\ddagger}$ NCI plot surfaces $(s=0.3,-0.03$ a.u. $)<\operatorname{sign}\left(\lambda_{2}\right) \rho<0.03$ a.u.) of attractive, repulsive and nonbonding interactions are materialized by blue, red and green isosurfaces respectively (atom color code: light grey, C; dark blue, N; white, H; red, O; violet, Co). 
* The IQA energy partitioning method is a tool for investigating interatomic interactions by decomposition into covalent and ionic energy contributions. Based on real-space partitioning of the molecular space, this method, when extended to the Kohn-Sham DFT framework, gives access to a semi-quantitative partitioning of energy contributions of exchange-correlation and of coulombic interaction terms for two-atom interactions within a molecule. The interatomic interaction energy $E_{\text {int }}{ }^{A B}$ is the sum of a covalent $E_{\text {covalent }}{ }^{A B}$ and an ionic contribution $E_{\text {ionic }}{ }^{A B}$ : $E_{\text {int }}{ }^{A B}=E_{\text {ionic }}{ }^{A B}+E_{\text {covalent }}{ }^{A B}$ with $E_{\text {ionic }}{ }^{A B}=E_{N N}{ }^{A B}+E_{e N}{ }^{A B}[\rho]+E_{N e}{ }^{A B}[\rho]+E_{\text {eeCl }}{ }^{A B}[\rho]$ and $E_{\text {covalent }}{ }^{\mathrm{AB}}=$ $E_{e e X}{ }^{A B}\left[\left\{\psi_{i}^{K S}\right\}\right] . E_{\mathrm{NN}}{ }^{\mathrm{AB}}$, is the repulsion energy between nuclei in $\mathrm{A}$ and $\mathrm{B}, E_{\mathrm{eN}}{ }^{\mathrm{AB}}$ is the attraction of the electrons in $\mathrm{A}$ by the nucleus in $\mathrm{B}, E_{\mathrm{Ne}}{ }^{\mathrm{AB}}$ is the reciprocal $\mathrm{B}$ electrons attraction with nucleus $\mathrm{A}$ and $E_{\mathrm{eeCl}}{ }^{\mathrm{AB}}$ is the classical electrostatic electronic repulsion energy contribution. The $E_{\text {covalent }}{ }^{\mathrm{AB}}=E_{e e X}{ }^{A B}\left[\left\{\psi_{i}^{K S}\right\}\right]$ is the exchange contribution. IQA does not account for the contribution of LDF.

"The "reactive site" is defined primarily as the local group of atoms in a reactant complex directly taking part to a given chemical reaction. The notion of reactive site extends to all key intermediates and transition state when the considered reaction is confined to a molecular assembly/molecular complex.

\# IBSI is a quantitative index allowing to intra-molecularly probe the "strength" of a given covalent bond or weaker (non-covalent) interaction also based on the so-called Independent Gradient Model. Noncovalent interactions (NCIs) are evidenced by $0<$ IBSI $<0.15$, transitionmetal coordination bond by $0.15<$ IBSI $<0.60$, and covalent bonding by $0.15<$ IBSI $<4.0$ values. The IGM- $\delta g^{\text {inter }}$ descriptor can be seen as a measure of the electron sharing caused by the electron density interference between two user-defined fragments. It assesses the mutual density penetration by the deviation of the true electron density gradient from a non-interacting reference, i.e. the independent gradient model bearing the same electron density as the real system. Integrating this descriptor gives rise to the $\Delta g^{\text {inter }}$ interaction score that measures the interaction between two user-defined fragments. Like many QTAIM-based analytical methods the $\Delta g^{\text {inter }}$ score and IBSI are free of issues related to BSSE.

Acknowledgements. We acknowledge the funding and support provided by the Centre National de la Recherche Scientifique, the Agence Nationale de la Recherche, the Complex System Chemistry Labex and the University of Strasbourg. J.P.D. thanks the Alexander von Humboldt foundation for its continued support.

Yann Cornaton, born in 1987 (France), obtained his Ph.D. in theoretical chemistry from the University of Strasbourg under the supervision of Roberto Marquardt and Emmanuel Fromager 
in 2013. He joined Kenneth Ruud's group at the University of Tromsø/Arctic University of Norway as a post-doctoral fellow in 2016-2019. Hired as Associate Professor at the University of Perpignan Via Domitia in 2016, he moved to the group of Jean-Pierre Djukic at the University of Strasbourg in 2019. His current research interests focus on the theoretical studies of organometallic and organic systems and the investigation of noncovalent interactions.

Jean-Pierre Djukic, born near Paris in 1967, obtained a PhD in chemistry from the University Pierre and Marie Curie in Paris under the supervision of Eric Rose in 1992. He was postdoctoral research fellow at the Iowa State University in 1993-94 in the group of L. Keith Woo. He was hired as researcher at the Centre National de la Recherche Scientifique (CNRS) in Strasbourg in the group of Michel Pfeffer in 1994. In 1996-97 he was a A. von Humboldt foundation fellow in the group of Karl-Heinz Dötz at the University of Bonn. Since 2014 he heads as Director of Research the Laboratory of Organometallic Chemistry and Systemics of the Institute of Chemistry of Strasbourg. His research interests span mechanistic studies, experimental and theoretical studies of noncovalent interactions in homogeneous catalysis, in organic and organometallic chemistry.

Abbreviations. AMLA Ambiphilic Metal-Ligand Activation, BSSE basis set superposition error, cod cyclooctadiene, CMD Concerted Metalation Deprotonation, DFT density functional theory, DFT-D dispersion-corrected DFT, DLPNO-CCSD(T) perturbative triples correction (T) algorithm for domain based local pair-natural orbital singles and doubles coupled cluster, EHMO extended Hückel molecular orbital method, ESP electrostatic potential, HF Hartree-Fock, IBSI intrinsic bond strength index, IGM independent gradient model, IQA interacting quantum atoms, LED local energy decomposition, LEF local electric field, LDF London dispersion force, $n b d$ norbornadiene, NCI(s) noncovalent interaction(s), NMR nuclear magnetic resonance, phpy 2phenylenepyridine ligand, QTAIM quantum theory of atoms in molecule, RC reactant complex, SCS-MP2 spin component-scaled Møller-Plesset second order perturbative method, TS transition state, vdW van der Waals, WFT wave function theory, XRDA X-ray diffraction analysis. 


\section{REFERENCES}

(1) (a) Grimme, S.; Djukic, J.-P., Cation-Cation "Attraction": When London Dispersion Attraction Wins over Coulomb Repulsion Inorg. Chem. 2011, 50, 2619-2628. (b) Werle, C.; Bailly, C.; Karmazin-Brelot, L.; Le Goff, X.-F.; Ricard, L.; Djukic, J.-P., Hemichelation, a way to stabilize electron-unsaturated complexes: the case of T-shaped Pd and Pt metallacycles $\mathrm{J}$. Am. Chem. Soc. 2013, 135, 17839-17852.

(2) (a) Cornaton, Y.; Djukic, J.-P., A noncovalent interaction insight onto the concerted metallation deprotonation mechanism Phys. Chem. Chem. Phys. 2019, 21, 20486-20498. (b) Wu, F.; Deraedt, C.; Cornaton, Y.; Contreras-Garcia, J.; Boucher, M.; Karmazin, L.; Bailly, C.; Djukic, J.-P., Making Base-Assisted C-H Bond Activation by $\mathrm{Cp}{ }^{*} \mathrm{Co}$ (III) Effective: A Noncovalent Interaction-Inclusive Theoretical Insight and Experimental Validation Organometallics 2020, 39, 2609-2629.

(3) (a) Caldeweyher, E.; Mewes, J.-M.; Ehlert, S.; Grimme, S., Extension and evaluation of the D4 London-dispersion model for periodic systems Phys. Chem. Chem. Phys. 2020, 22, 84998512. (b) Bursch, M.; Caldeweyher, E.; Hansen, A.; Neugebauer, H.; Ehlert, S.; Grimme, S., Understanding and Quantifying London Dispersion Effects in Organometallic Complexes Acc. Chem. Res. 2019, 52, 258-266.

(4) Eyring, H., Steric Hindrance and Collision Diameters J. Am. Chem. Soc. 1932, 54, 31913203.

(5) Eisenschitz, R.; London, F., Uber das Verhaltnis der van der Waalsschen Krafte zu den homopolaren Bindungskraften Z. Phys. 1930, 60, 491-527.

(6) Bunnett, J. F., A New Factor Affecting Reactivity in Bimolecular Nucleophilic Displacement Reactions J. Am. Chem. Soc. 1957, 79, 5969-5974.

(7) Spinner, E., Intramolecular van der Waals-London cohesions and chemical reactivity: the transition state in the bimolecular nucleophilic displacement reaction of halide ion with alkyl halide Aust. J. Chem. 1960, 13, 218-221.

(8) (a) Bunnet, J. F.; Reinheimer, J. D., ortho Effects in Reactions of Nucleophiles with Benzyl Chlorides J. Am. Chem. Soc. 1962, 84, 3284-3288. (b) Sisti, A. J.; Sawinski, J. P., London force and related coulombic interactions in the displacement reaction with substituted benzyl chlorides 
J. Org. Chem. 1976, 41, 2746-2749. (c) Bartoli, G.; Todesco, P. E.; Fiorentino, M., Reactions of 2, 4-dinitrohalobenzenes with nucleophiles. A new correlation between reactivities and substrate polarizability J. Am. Chem. Soc. 1977, 99, 6874-6878.

(9) (a) Chatley, H., Cohesion Nature 1921, 107, 786-787. (b) Coulson, C. A., Interatomic Forces: Maxwell to Schrödinger Nature 1962, 195, 744-749.

(10) (a) Politzer, P.; Toro-Labbé, A.; Gutierrez-Oliva, S.; Herrera, B.; Jaque, P.; Concha, M. C.; Murray, J. S., The reaction force: Three key points along an intrinsic reaction coordinate $J$. Chem. Sci. 2005, 117, 467-472. (b) Toro-Labbé, A.; Gutiérrez-Oliva, S.; Murray, J. S.; Politzer, P., A new perspective on chemical and physical processes: the reaction force Mol. Phys. 2007, 105, 2619-2625. (c) Laplaza, R.; Boto, R. A.; Contreras-García, J.; Montero-Campillo, M. M., Steric clash in real space: biphenyl revisited Phys. Chem. Chem. Phys. 2020, 22, 21251-21256.

(11) (a) Power, P. P., An Update on Multiple Bonding between Heavier Main Group Elements: The Importance of Pauli Repulsion, Charge-Shift Character, and London Dispersion Force Effects Organometallics 2020, 39, 4127-4138. (b) Paenurk, E.; Gershoni-Poranne, R.; Chen, P., Trends in Metallophilic Bonding in Pd-Zn and Pd-Cu Complexes Organometallics 2017, 36, 4854-4863. (c) Liptrot, D. J.; Power, P. P., London dispersion forces in sterically crowded inorganic and organometallic molecules Nat. Rev. Chem. 2017, 1, 0004pp.

(12) (a) Burton, R.; Green, M. L. H.; Abel, E. W.; Wilkinson, G., Some new organo-iron complexes Chem. Ind. 1958, 1592. (b) Burton, R.; Wilkinson, G., Azulene-metal complex Chem. Ind. 1958, 1205.

(13) Churchill, M. R.; Bird, P. H., Crystallographic studies on molybdenum-azulene complexes Chem. Commun. 1967, 746-747.

(14) (a) Edelmann, F.; Tofke, S.; Behrens, U., Transition metal-fulvene complexes. XXV. Synthesis and structure of binuclear azulene-chromium complexes J. Organomet. Chem. 1986, 308, 27-34. (b) Toefke, S.; Behrens, U., Transition metal-fulvene complexes. 30. Azulene as an unusual $\eta^{6}$-ligand and a $\eta^{6}: \eta^{4}$-bridge Angew. Chem. 1987, 99, 134-135. (c) Toefke, S.; Behrens, U., Transition metal fulvene complexes. XXXII. Heteronuclear binuclear complexes of azulenes J. Organomet. Chem. 1988, 338, 29-45.

(15) Contreras-García, J.; Johnson, E. R.; Keinan, S.; Chaudret, R.; Piquemal, J.-P.; Beratan, D. N.; Yang, W., NCIPLOT: A Program for Plotting Noncovalent Interaction Regions J. Chem. Theory Comput. 2011, 7, 625-632. 
(16) (a) Schwabe, T.; Grimme, S.; Djukic, J.-P., Noncovalent Metal-Metal Interactions: The Crucial Role of London Dispersion in a Bimetallic Indenyl System J. Am. Chem. Soc. 2009, 131, 14156-14157. (b) Grimme, S.; Djukic, J.-P., The Crucial Role of Dispersion in the Cohesion of Nonbridged Binuclear Os $\rightarrow \mathrm{Cr}$ and Os $\rightarrow \mathrm{W}$ Adducts Inorg. Chem. 2010, 49, 2911-2919.

(17) (a) Ceccon, A.; Gambaro, A.; Santi, S.; Venzo, A., On different chemical and catalytic behavior of ( $\eta$-indenyl)( $\eta 4-1,5$-cyclooctadienyl)rhodium and $\left(\eta^{4}-1,5\right.$-cyclooctadienyl)rhodium $(\mu$ ๆ:१-indenyl)chromium tricarbonyl complexes J. Mol. Catal. 1991, 69, L1-L6. (b) Mantovani, L.; Ceccon, A.; Gambaro, A.; Santi, S.; Ganis, P.; Venzo, A., Heterobimetallic Indenyl Complexes. Mechanism of Cyclotrimerization of Dimethyl Acetylenedicarboxylate (DMAD) Catalyzed by trans- $\left[\mathrm{Cr}(\mathrm{CO})_{3}(\right.$ Heptamethylindenyl $\left.) \mathrm{Rh}(\mathrm{CO})_{2}\right]$ Organometallics 1997, 16, 26822690.

(18) Ceccon, A.; Gambaro, A.; Santi, S.; Valle, G.; Venzo, A., Synthesis and characterization of $\eta^{6}$-tricarbonylchromium-indenyl- $\eta^{3}$-rhodium- $\eta^{4}$-cyclooctadiene: an $\eta^{3}: \eta^{6}$ coordination for the indenyl ligand J. Chem. Soc., Chem. Commun. 1989, 51-53.

(19) Bonifaci, C.; Ceccon, A.; Gambaro, A.; Ganis, P.; Santi, S.; Valle, G.; Venzo, A., Heterobimetallic indenyl complexes. Synthesis and structure of cis- $\left[\mathrm{Cr}(\mathrm{CO})_{3}\right.$ (indenyl) $\mathrm{RhL}_{2}\left(\mathrm{~L}_{2}=\right.$ norbornadiene, $\left.(\mathrm{CO})_{2}\right)$ Organometallics 1993, 12, 4211-4214.

(20) Bonifaci, C.; Ceccon, A.; Gambaro, A.; Ganis, P.; Santi, S.; Venzo, A., Heterobimetallic Indenyl Complexes. The Trans-Cis Isomerization of $\operatorname{Cr}(\mathrm{CO})_{3}(\mu, \eta: \eta$-indenyl $) \operatorname{Rh}(\mathrm{NBD})$ Organometallics 1995, 14, 2430-2434.

(21) Bonifaci, C.; Ceccon, A.; Gambaro, A.; Ganis, P.; Santi, S.; Valle, G.; Venzo, A., Heterobimetallic indenyl complexes. Synthesis and structure of syn- $\left[\mathrm{Cr}(\mathrm{CO})_{3}(\mu, \eta: \eta-\right.$ indenyl)Rh(COD)] J. Organomet. Chem. 1995, 492, 35-39.

(22) Bonifaci, C.; Ceccon, A.; Santi, S.; Mealli, C.; Zoellner, R. W., Cofacial and antarafacial indenyl bimetallic isomers: a descriptive MO picture and implications for the indenyl effect on ligand substitution reactions Inorg. Chim. Acta 1995, 240, 541-549.

(23) Petrovic, P.; Djukic, J.-P.; Hansen, A.; Bannwarth, C.; Grimme, S. In Non-Covalent Interactions in the Synthesis and Design of New Compounds; Maharramov, A. M., Mahmudov, K. T., Kopylovich, M. N., Pombeiro, A. J. L., Eds.; John Wiley \& Sons, Inc.: Hoboken, New Jersey, 2016, p 115-144. 
(24) Werle, C.; Dohm, S.; Bailly, C.; Karmazin, L.; Ricard, L.; Sieffert, N.; Pfeffer, M.; Hansen, A.; Grimme, S.; Djukic, J.-P., Trans-cis C-Pd-C rearrangement in hemichelates Dalton Trans. 2017, 46, 8125-8137.

(25) Langmuir, I., Types of Valence Science 1921, 54, 59-67.

(26) Chung, C.-S., The entropy effect of chelation Inorg. Chem. 1979, 18, 1321-1324.

(27) (a) Kalinin, V. N.; Cherepanov, I. A.; Moiseev, S. K.; Batsanov, A. S.; Struchkov, Y. T., Reactivity of $\alpha$-metalated alkylarene tricarbonylchromium complexes. Preparation, properties and x-ray crystal structure of [cyclic] $\left(\eta^{3}-\mathrm{C}_{3} \mathrm{H}_{5}\right) \mathrm{Pd}\left(\mathrm{CH}_{2} \mathrm{Ph}-\eta^{6}\right)-\mathrm{Cr}(\mathrm{CO})_{3}$, a novel complex with a palladium-chromium $\sigma$-bond Mendeleev Commun. 1991, 77-78. (b) Kalinin, V. N.; Cherepanov, I. y. A.; Moiseev, S. K.; Dolgushin, F. M.; Yanovsky, A. I.; Struchkov, Y. T., 2- $\eta^{3}-$ Allyl-1,1,1-tricarbonyl- $\mu-\left(\eta^{1}: \eta^{6}\right.$-diphenylmethyl)chromium palladium(Pd-Cr) at $130 \mathrm{~K}$ Acta Crystallogr., Sect. C: Cryst. Struct. Commun. 1993, C49, 805-808.

(28) (a) Werle, C.; Hamdaoui, M.; Bailly, C.; Le Goff, X.-F.; Brelot, L.; Djukic, J.-P., ElectronDeficient $\eta^{1}$-Indenyl, $\eta^{3}$-allylpalladium(II) Complexes Stabilized by Fluxional Non-covalent Interactions J. Am. Chem. Soc. 2013, 135, 1715-1718. (b) Werle, C.; Bailly, C.; KarmazinBrelot, L.; Le Goff, X.-F.; Pfeffer, M.; Djukic, J.-P., First Stabilization of 14-Electron Rhodium(I) Complexes by Hemichelation Angew. Chem., Int. Ed. 2014, 53, 9827-9831. (c) Werle, C.; Karmazin, L.; Bailly, C.; Ricard, L.; Djukic, J.-P., Stabilization of an ElectronUnsaturated Pd(I)-Pd(I) Unit by Double Hemichelation Organometallics 2015, 34, 3055-3064. (d) Werle, C.; Anstine, D. M.; Karmazin, L.; Bailly, C.; Ricard, L.; Djukic, J.-P., New Pd(II) hemichelates devoid of incipient bridging CO $\cdots \mathrm{Pd}$ interactions Dalton Trans. 2016, 45, 607617. (e) Werle, C.; Karmazin, L.; Bailly, C.; Djukic, J.-P., Effect of Enhanced Electron Withdrawal on the Cohesion of Cr-Pd Hemichelates Eur. J. Inorg. Chem. 2019, 2019, 33013308.

(29) (a) Djukic, J.-P.; Maisse, A.; Pfeffer, M.; Doetz, K.-H.; Nieger, M., First synthesis and structural characterization of neutral chelated syn-facial bimetallic $\left(\eta^{5}\right.$ cyclohexadienyl)benzylidene complexes from tetracarbonyl[2- $\left\{\left(\eta^{6}-\right.\right.$ phenyl)tricarbonylchromium $\left.(0)-\kappa_{2} \mathrm{C}_{2}^{\prime}\right\}$ pyridine- $\mathrm{N}$ ]manganese(I) derivatives Eur. J. Inorg. Chem. 1998, 1781-1790. (b) Djukic, J.-P.; Maisse-Francois, A.; Pfeffer, M.; Doetz, K. H.; De Cian, A.; Fischer, J., Organometallic Helices: The Mechanism of Formation of "Metallospiralenes" Organometallics 2000, 19, 5484-5499. (c) Djukic, J.-P.; Michon, C.; 
Maisse-Francois, A.; Allagapen, R.; Pfeffer, M.; Dotz, K. H.; De Cian, A.; Fischer, J., Chiral "metallo-spiralenes": helical molecules conformationally stabilised by an organometallic scaffold Chem. - Eur. J. 2000, 6, 1064-1077. (d) Djukic, J.-P.; Michon, C.; Berger, A.; Pfeffer, M.; de Cian, A.; Kyritsakas-Gruber, N., Synthesis of syn-facial (Cr,Mn) benzyl complexes by the stereoselective thermolytic coupling of unsymmetric diazomethanes with cyclomanganated $\left(\eta^{6}\right.$ arene)tricarbonylchromium complexes J. Organomet. Chem. 2006, 691, 846-858. (e) Werle, C.; Le Goff, X.-F.; Djukic, J.-P., Unusual outcome of the thermolytic condensation of diazoarylmethanes with a [tricarbonyl $\left(\eta^{6}-2-p\right.$-tolyl)chromium]-oxazolyl chelate of tetracarbonylrhenium J. Organomet. Chem. 2014, 751, 754-759.

(30) Sieffert, N., Molecular motions in a fluxional ( $\eta^{6}$-indenyl)tricarbonylchromium hemichelate: a density functional theory molecular dynamics study Dalton Trans. 2018, 47, 8906-8920.

(31) (a) Guevara-Vela, J. M.; Francisco, E.; Rocha-Rinza, T.; Martín Pendás, Á., Interacting Quantum Atoms-A Review Molecules 2020, 25, 4028. (b) this report.

(32) Bader, R. F. W. In Atoms in Molecules: A Quantum Theory; Clarendon: Oxford, 1990.

(33) Djukic, J.-P.; Pfeffer, M.; Doetz, K. H., Slackening a chromium carousel with a manganese bridle: selective ${ }^{13} \mathrm{C}$ isotopic labelling applied to the determination of the steric barrier to rotation of a $\mathrm{Cr}(\mathrm{CO})_{3}$ group in a syn-facial hetero-bimetallic $(\mathrm{Cr}, \mathrm{Mn})$ cyclohexadienylbenzylidene complex C. R. Acad. Sci., Ser. IIc: Chim. 1999, 2, 403-408.

(34) Hyla-Kryspin, I.; Grimme, S.; Djukic, J.-P., The Cr-Mn Interaction in syn-Facial [Tricarbonyl(benzyl)chromium]manganesetricarbonyl Complexes: A Non-Covalent Metal-Metal Bond Organometallics 2009, 28, 1001-1013.

(35) Einstein, F. W. B.; Jones, T.; Pomeroy, R. K.; Rushman, P., 18-Electron complexes as ligands. Synthesis, structure, and stereochemical nonrigidity of (trimethylphosphine)tetracarbonylosmium-pentacarbonyltungsten complex $\left(\left(\mathrm{Me}_{3} \mathrm{P}\right)(\mathrm{OC})_{4} \mathrm{OsW}(\mathrm{CO})_{5}\right)$ J. Am. Chem. Soc. 1984, 106, 2707-2708.

(36) Nakatsuji, H.; Hada, M.; Kawashima, A., Electronic structures of dative metal-metal bonds; $\mathrm{Ab}$ initio molecular orbital calculations of $(\mathrm{OC})_{5} \mathrm{Os}-\mathrm{M}(\mathrm{CO})_{5}(\mathrm{M}=$ tungsten, chromium $)$ in comparison with $(\mathrm{OC})_{5} \mathrm{M}-\mathrm{M}(\mathrm{CO})_{5}(\mathrm{M}=$ rhenium, manganese $) \quad$ Inorg. Chem. 1992, 31, 17401744. 
(37) Mann, K. R.; Lewis, N. S.; Williams, R. M.; Gray, H. B.; Gordon, J. G., II, Further studies of metal-metal bonded oligomers of rhodium(I) isocyanide complexes. Crystal structure analysis of octakis(phenyl isocyanide)dirhodium bis(tetraphenylborate) Inorg. Chem. 1978, 17, 828-834. (38) (a) Miskowski, V. M.; Smith, T. P.; Loehr, T. M.; Gray, H. B., Properties of metal-metal single bonds. Vibrational and electronic spectra of binuclear rhodium(II) and iridium(II) isocyanide complexes with comparisons to decacarbonyldimanganese $\left[\mathrm{Mn}_{2}(\mathrm{CO})_{10}\right] \mathrm{J} . \mathrm{Am}$. Chem. Soc. 1985, 107, 7925-7934. (b) Novoa, J. J.; Aullon, G.; Alemany, P.; Alvarez, S., On the Bonding Nature of the M-M Interactions in Dimers of Square-Planar Pt(II) and Rh(I) Complexes J. Am. Chem. Soc. 1995, 117, 7169-7171.

(39) Mann, K. R.; Gordon, J. G., II; Gray, H. B., Characterization of oligomers of tetrakis(phenyl isocyanide)rhodium(I) in acetonitrile solution J. Am. Chem. Soc. 1975, 97, 35533555.

(40) Yepes, D.; Munarriz, J.; Daniel, 1. A.; Contreras-Garcia, J.; Jaque, P., Real-Space Approach to the Reaction Force: Understanding the Origin of Synchronicity/Nonsynchronicity in Multibond Chemical Reactions J. Phys. Chem. A 2020, 124, 1959-1972.

(41) Stuyver, T.; Ramanan, R.; Mallick, D.; Shaik, S., Oriented (Local) Electric Fields Drive the Millionfold Enhancement of the H-Abstraction Catalysis Observed for Synthetic Metalloenzyme Analogues Angew. Chem., Int. Ed. 2020, 59, 7915-7920.

(42) Lu, Q.; Neese, F.; Bistoni, G., Formation of Agostic Structures Driven by London Dispersion Angew. Chem., Int. Ed. 2018, 57, 4760-4764.

(43) Davies, D. L.; Macgregor, S. A.; McMullin, C. L., Computational Studies of CarboxylateAssisted C-H Activation and Functionalization at Group 8-10 Transition Metal Centers Chem. Rev. 2017, 117, 8649-8709.

(44) Gandeepan, P.; Müller, T.; Zell, D.; Cera, G.; Warratz, S.; Ackermann, L., 3d Transition Metals for C-H Activation Chem. Rev. 2019, 119, 2192-2452.

(45) Jerhaoui, S.; Djukic, J.-P.; Wencel-Delord, J.; Colobert, F., Asymmetric, Nearly Barrierless $\mathrm{C}\left(s p^{3}\right)$-H Activation Promoted by Easily-Accessible N-Protected Aminosulfoxides as New Chiral Ligands ACS Catal. 2019, 9, 2532-2542.

(46) Hammarback, L. A.; Aucott, B. J.; Bray, J. T. W.; Clark, I. P.; Towrie, M.; Robinson, A.; Fairlamb, I. J. S.; Lynam, J. M., Direct Observation of the Microscopic Reverse of the 
Ubiquitous Concerted Metalation Deprotonation Step in C-H Bond Activation Catalysis J. Am. Chem. Soc. 2021, 143, 1356-1364.

(47) Alharis, R. A.; McMullin, C. L.; Davies, D. L.; Singh, K.; Macgregor, S. A., Understanding electronic effects on carboxylate-assisted $\mathrm{C}-\mathrm{H}$ activation at ruthenium: the importance of kinetic and thermodynamic control Faraday Discussions 2019, 220, 386-403.

(48) Wieduwilt, E. K.; Boisson, J.-C.; Terraneo, G.; Hénon, E.; Genoni, A., A Step toward the Quantification of Noncovalent Interactions in Large Biological Systems: The Independent Gradient Model-Extremely Localized Molecular Orbital Approach J. Chem. Inf. Model. 2021, 61, 795-809.

(49) Klein, J.; Khartabil, H.; Boisson, J.-C.; Contreras-García, J.; Piquemal, J.-P.; Hénon, E., New Way for Probing Bond Strength J. Phys. Chem. A 2020, 124, 1850-1860.

(50) Wu, F.; Deraedt, C.; Cornaton, Y.; Ruhlmann, L.; Karmazin, L.; Bailly, C.; Kyritsakas, N.; Le Breton, N.; Choua, S.; Djukic, J.-P., Fate of Cobaltacycles in $\mathrm{Cp}^{*} \mathrm{Co}-$ Mediated $\mathrm{C}-\mathrm{H}$ Bond Functionalization Catalysis: Cobaltacycles May Collapse upon Oxidation via Co(IV) Species Organometallics 2021, 40, 2624-2642.

(51) López-Resano, S.; Martínez de Salinas, S.; Garcés-Pineda, F. A.; Moneo-Corcuera, A.; Galán-Mascarós, J. R.; Maseras, F.; Pérez-Temprano, M. H., Redefining the Mechanistic Scenario of Carbon-Sulfur Nucleophilic Coupling via High-Valent Cp*CoIV Species Angew. Chem. Int. Ed. 2021, 60, 11217-11221.

(52) Werner, A., Zur Kenntnis des asymmetrischen Kobaltatoms. V Ber. deutsch. chem. Ges. 1912, 45, 121-130. 